\title{
Development of Software Defined Radio Protocol for Acoustic Communication on Pipes
}

Transmission of Information by Acoustic Communication along Metal Pathways in Nuclear Facilities

Nuclear Science and Engineering Division 


\section{About Argonne National Laboratory}

Argonne is a U.S. Department of Energy laboratory managed by UChicago Argonne, LLC under contract DE-AC02-06CH11357. The Laboratory's main facility is outside Chicago, at 9700 South Cass Avenue, Argonne, Illinois 60439. For information about Argonne and its pioneering science and technology programs, see www.anl.gov.

\section{DOCUMENT AVAILABILITY}

Online Access: U.S. Department of Energy (DOE) reports produced after 1991 and a growing number of pre-1991 documents are available free at OSTI.GOV (http://www.osti.gov/), a service of the US Dept. of Energy's Office of Scientific and Technical Information.

Reports not in digital format may be purchased by the public from the National Technical Information Service (NTIS):

U.S. Department of Commerce

National Technical Information Service

5301 Shawnee Rd

Alexandria, VA 22312

www.ntis.gov

Phone: (800) 553-NTIS (6847) or (703) 605-6000

Fax: (703) 605-6900

Email:orders@ntis.gov

Reports not in digital format are available to DOE and DOE contractors from the Office of Scientific and Technical Information (OSTI):

U.S. Department of Energy

Office of Scientific and Technical Information

P.O. Box 62

Oak Ridge, TN 37831-0062

www.osti.gov

Phone: (865) 576-8401

Fax: (865) 576-5728

Email: reports@osti.gov

\section{Disclaimer}

This report was prepared as an account of work sponsored by an agency of the United States Government. Neither the United States Government nor any agency thereof, nor UChicago Argonne, LLC, nor any of their employees or officers, makes any warranty, express or implied, or assumes any legal liability or responsibility for the accuracy, completeness, or usefulness of any information, apparatus, product, or process disclosed, or represents that its use would not infringe privately owned rights. Reference herein to any specific commercial product, process, or service by trade name, trademark, manufacturer, or otherwise, does not necessarily constitute or imply its endorsement, recommendation, or favoring by the United States Government or any agency thereof. The views and opinions of document authors expressed herein do not necessarily state or reflect those of the United States Government or any agency thereof, Argonne National Laboratory, or UChicago Argonne, LLC. 


\section{Development of Software Defined Radio Protocol for Acoustic Communication on Pipes}

Transmission of Information by Acoustic Communication Along Metal Pathways in Nuclear Facilities

prepared by

Dmitry Shribak ${ }^{1,2}$, Alexander Heifetz ${ }^{1}$, Xin Huang ${ }^{1}$

${ }^{1}$ Nuclear Science and Engineering Division, Argonne National Laboratory

${ }^{2}$ Department of Physics, University of Chicago, Chicago, IL 60637

August 16, 2018 


\section{Introduction}

Nuclear Science Engineering Division at Argonne has been developing a new method of transmitting information via acoustic waves on pipes in a nuclear facility. This method provides the capability to communicate information from within the containment building under the conditions of total power outage following a severe accident. Compared to traditional RF communications, acoustic communications allows for signal transmission across thick concrete barriers, and better information security due to spatial confinement of the signal. Data of interest consists of sensor readings, voice, and images. Transmission of images is most challenging because corruption of the header string might render the reconstructed image unreadable.

In order to achieve this task, we used the Software Defined Radio tool GNURadio, which allowed us to build a communication protocol to transmit data effectively. We created a python tool to compare different modulation and front error correction techniques used to transferring header files. The goal of this task was to successfully transmit the header file of a .ppm (Portable Pixel Map) image because any corruption in this data renders the image useless.

We first consider introduce the theoretical background of the physical communication system, modulation technique and data transmission protocol in Section I. Section II considers the specific experimental setup employed, emphasizing the implemented protocol. Following that, Section III outlines the function of each step in the GNURadio program and how the improvements to the system were quantified. Section IV analyses the results of the trials and highlights further potential improvements to the overall communication system.

\section{Background}

Our project combines the fields of acoustics with communication technology. It consists of three main layers: Physical Transmission, Modulation and Data Protocol.

Physical Transmission

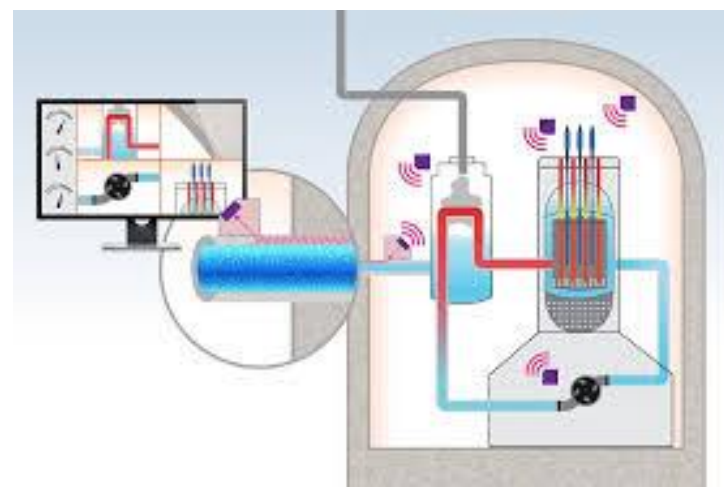

Image 1: Reactor Layout with attached technology (from "Realizing a Pipe Dream," https://www.anl.gov/articles/realizing-pipe-dream)

The overall challenge that this project aims to overcome is to maintain communication with a nuclear reactor reaction core incase of a meltdown, which is isolated by a few meters of 
concrete to protect against radiation. However, there are steam pipes penetrating this confinement shell. This pipe will form the channel for our communication system.

For the physical transmission, we employed two ultrasonic acoustic wave transducers on six foot steel pipe spaced at about five feet apart. The transducers were originally designed for nondestructive testing. On the physical layer, a digital wave is generated by the GNURadio program, which is next converted into an analog wave by Red Pitaya. This analog wave is sent to the transducer through an amplifier, which converts it into an acoustic wave by vibrating a crystal at a certain frequency. This vibration passes through the pipe in the form of a shear mechanical wave and vibrates the transducer on the other end of the pipe, generating an electrical wave, which is converted back into a digital wave by Red Pitaya.

\section{Modulation}

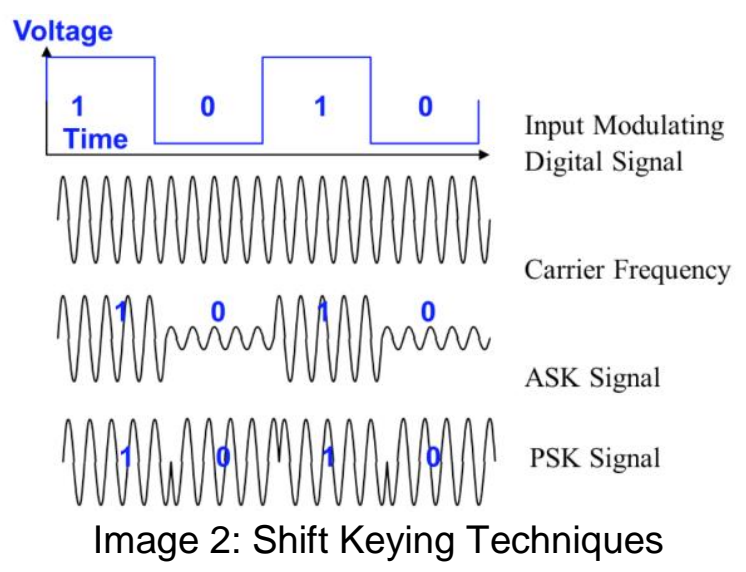

Digital modulation is the process sending a binary signal inside of a different signal that can be easily transmitted over a physical channel. In our case, we chose to employ binary Amplitude Shift Keying (ASK) and binary Phase Shift Keying (PSK).

In ASK, a 1 is represented as a high amplitude, and a 0 is represented by a low amplitude. In PSK, a 1 is represented by a 180 degree phase shift on the carrier frequency, and a 0 is represented by a 0 degree phase shift on the carrier frequency.

The binary waveform is multiplied onto a carrier frequency, produced by the Red Pitaya, and transmitted through the pipe. On the receiving end, the signal is demodulated by multiplying again by the carrier frequency and passing the information through a low pass filter to recover the original signal.

These are the most simple forms of modulation available, and while more elaborate forms of Shift Keying exist that allow for more information to be encoded per key, we chose this technique due to the fact that the constellation symbols are maximally spread out, reducing the impact of noise on the channel compared to a setup that encodes more than one bit per symbol. 


\section{Protocol}

Outside of being modulated and passing through the physical channel, the image data has to be processed in order to be successfully transmitted and recovered. As noted above, only a binary stream of information can be sent through the pipe. However, image data has a non-binary data structure and for that we have chosen to use a Portable Pixel Map (PPM) file as our primary image data structure for transmission.

$$
\begin{array}{ll}
\text { P3 } & <- \text { - file type } \\
44 & <- \text { dimensions in pixels } \\
255 & <- \text { maximum pixel value ( } r g b \text { is } 0 \text { to 255) } \\
110 & \\
412 & \\
534 & \\
& \text { Table 1: Example of Header File }
\end{array}
$$

The PPM file type stores the image dimensions in the first three lines and the rest is the image itself as a matrix after that in the form of ASCII character. We will refer to these three lines as the "image header" and the rest as the "image payload". The image header is critical to successful recovery of the image, as if there are any errors within the file, the computer will not be able to read the data effectively. The image payload, on the other hand, can contain more errors as a single error is less likely to make the file unreadable.

In order to transmit this information, this data structure has to be converted into binary, sent, and reassembled back into its original form. To accomplish this task, we first disassemble the file into a stream of ASCII characters, in the form of bytes ( 1 byte $=8$ bits). A table of ASCII values is shown below: 


\begin{tabular}{|c|c|c|c|c|c|}
\hline ASCII C & Character & ASCII C & Character & ASCII & Character \\
\hline value & & value & & valu & ue \\
\hline 000 & -0 & 043 & + & 086 & $\mathbf{V}$ \\
\hline 001 & $-A$ & 044 & , & 087 & $H$ \\
\hline 002 & ${ }^{-} \mathrm{B}$ & 045 & - & 088 & $\mathbf{x}$ \\
\hline 003 & ${ }^{-} \mathrm{C}$ & 046 & - & 089 & $\mathbf{Y}$ \\
\hline 004 & ${ }^{-D}$ & 047 & $/$ & 090 & $\mathbf{Z}$ \\
\hline 005 & ${ }^{-} E$ & 048 & 0 & 091 & {[} \\
\hline 006 & ${ }^{-} \mathrm{F}$ & 049 & 1 & 092 & 1 \\
\hline 007 & ${ }^{-G}$ & 050 & 2 & 093 & ] \\
\hline 008 & ${ }^{-} \mathrm{H}$ & 051 & 3 & 094 & - \\
\hline 009 & ${ }^{-} I$ & 052 & 4 & 095 & - \\
\hline 010 & $-J$ & 053 & 5 & 096 & ' \\
\hline 011 & ${ }^{-} K$ & 054 & 6 & 097 & $\mathbf{a}$ \\
\hline 012 & ${ }^{-} L$ & 055 & 7 & 098 & $\mathbf{b}$ \\
\hline 013 & $-\mathrm{M}$ & 056 & 8 & 099 & c \\
\hline 014 & $-\mathbf{N}$ & 057 & 9 & 100 & d \\
\hline 015 & -0 & 158 & : & 101 & e \\
\hline 016 & ${ }^{-P}$ & 059 & ; & 102 & f \\
\hline 017 & $-Q$ & 060 & $<$ & 103 & $\mathbf{g}$ \\
\hline 018 & ${ }^{-} \mathrm{R}$ & 061 & $=$ & 104 & $\mathbf{h}$ \\
\hline 019 & -5 & 062 & $>$ & 105 & $i$ \\
\hline 020 & ${ }^{-T}$ & 063 & $?$ & 106 & $\mathrm{j}$ \\
\hline 021 & ${ }^{-} \mathrm{U}$ & 064 & (1) & 107 & $\mathbf{k}$ \\
\hline 022 & $-\mathrm{V}$ & 065 & A & 108 & 1 \\
\hline 023 & $-\mathrm{H}$ & 066 & B & 109 & m \\
\hline 024 & $-x$ & 067 & c & 110 & n \\
\hline 025 & ${ }^{-} \mathbf{Y}$ & 068 & D & 111 & 0 \\
\hline 026 & $-z$ & 069 & $\mathbf{E}$ & 112 & $\mathbf{p}$ \\
\hline 027 & -[ & 070 & $\mathbf{F}$ & 113 & $q$ \\
\hline 028 & -1 & 071 & G & 114 & $\mathbf{r}$ \\
\hline 029 & $-]$ & 072 & $\mathrm{H}$ & 115 & $\mathbf{s}$ \\
\hline 030 & $m$ & 073 & I & 116 & $\mathbf{t}$ \\
\hline 031 & - & 074 & $\mathbf{J}$ & 117 & $\mathbf{u}$ \\
\hline 032 & [space] & 075 & $\mathbf{K}$ & 118 & $\mathbf{v}$ \\
\hline 033 & ! & 076 & L & 119 & $\mathbf{v}$ \\
\hline 034 & $"$ & 077 & $\mathbf{M}$ & 120 & $\mathbf{x}$ \\
\hline 035 & $\#$ & 078 & $\mathbf{N}$ & 121 & $y$ \\
\hline 036 & $\$$ & 079 & D & 122 & $\mathbf{z}$ \\
\hline 037 & $\%$ & 080 & $\mathbf{P}$ & 123 & \{ \\
\hline 038 & $z$ & 081 & $Q$ & 124 & I \\
\hline 039 & ' & 082 & $\mathbf{R}$ & 125 & \} \\
\hline 040 & ( & 083 & $\mathbf{S}$ & 126 & - \\
\hline 041 & ) & 084 & $\mathrm{~T}$ & 127 & DEI. \\
\hline 042 & $*$ & 085 & $\mathbf{U}$ & & \\
\hline
\end{tabular}

Image 3: ASCII to number conversion table

These characters are then converted into a bit stream, a packet header is attached and is passed through the modulation methods mentioned earlier. After being demodulated, the bit stream is parse to remove the packet header, the bits are converted into their original bytes, and the file is reassembled.

When error correction is added, after the bytes are converted into bits they are multiplied by a convolution matrix, and once received, the bits are deconvoluted by an inverse matrix.

Overall, the protocol of the communication system was the primary focus of this project as reducing the number of errors in transmitting ensures that the communication system is reliable. 


\section{GNURadio implementation}

In order to implement the communication protocol, GNURadio was used as a base. Below is a flowgraph generated by GNURadio for ASK modulation with no convolutional code, followed by an explanation of each step in the process.

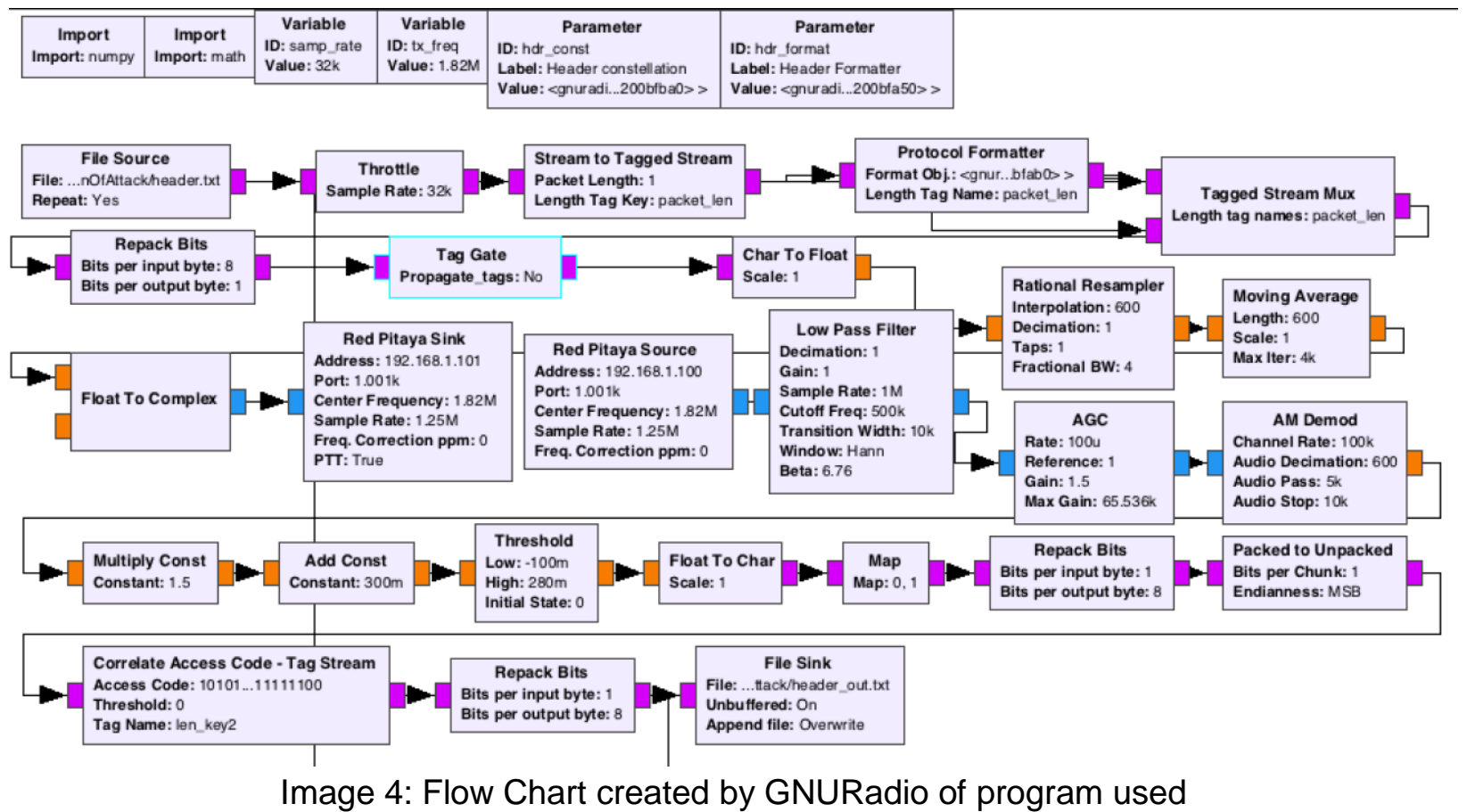

\section{Test and Analysis}

In order to compare the different data transmission techniques, a simple message was pass through the system and monitored on as information was passed through the blocks. Below is a representation of what occurs at each step in the process. Below is the plot for ASK.

In this example, we send a file with characters "Is!" for demonstration purposes. We will follow the journey of a packet as it is transmitted through the system. 


\section{File Source Output}

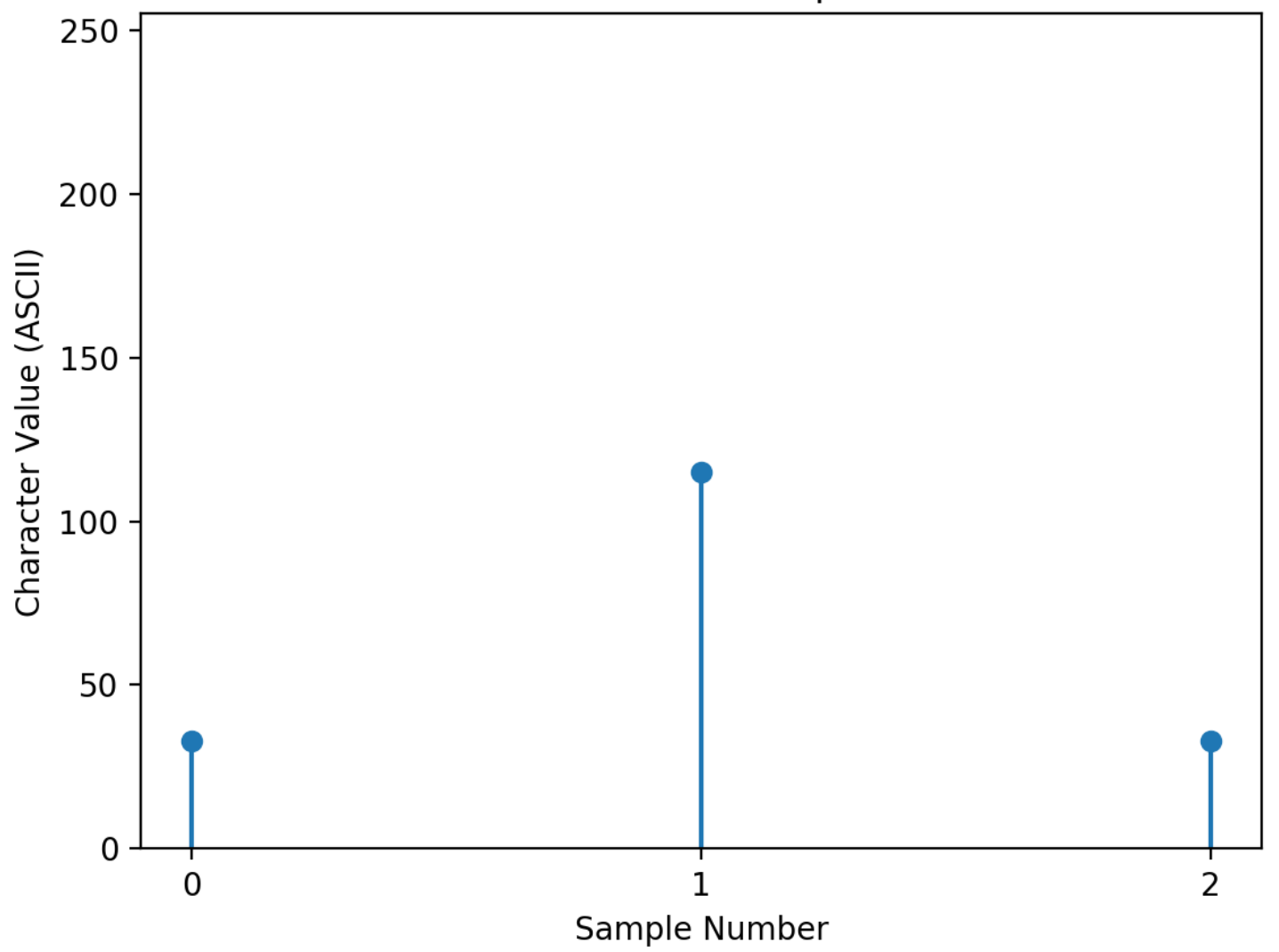

In the file source block, we see how file is being disassembled into three values: $33,115,33$. The value of 33 corresponds to "!" and the value of 115 corresponds to "s". Below is a diagram with each character labeled as a separate color. 
File Source Output (colors are individual bytes)

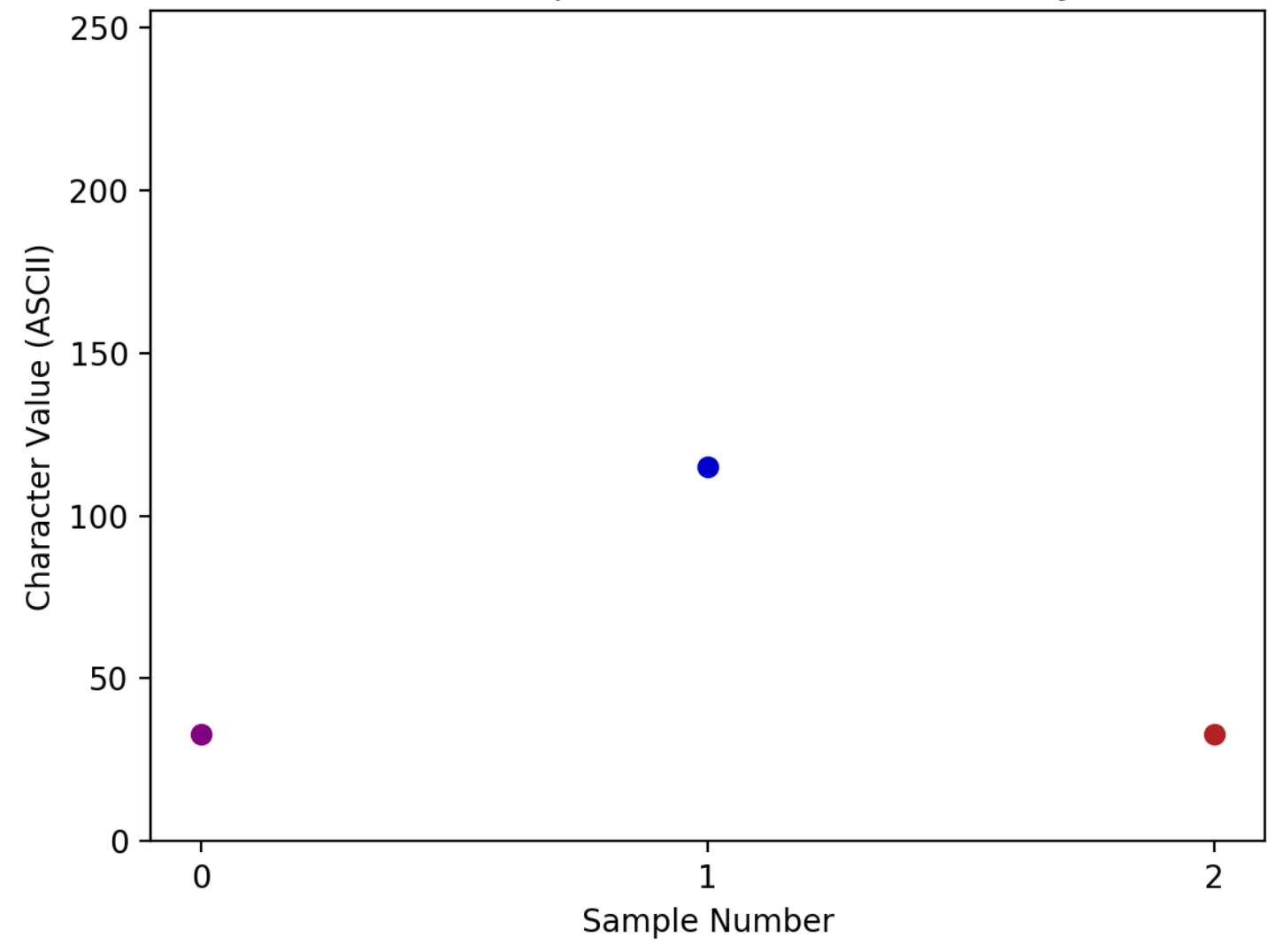




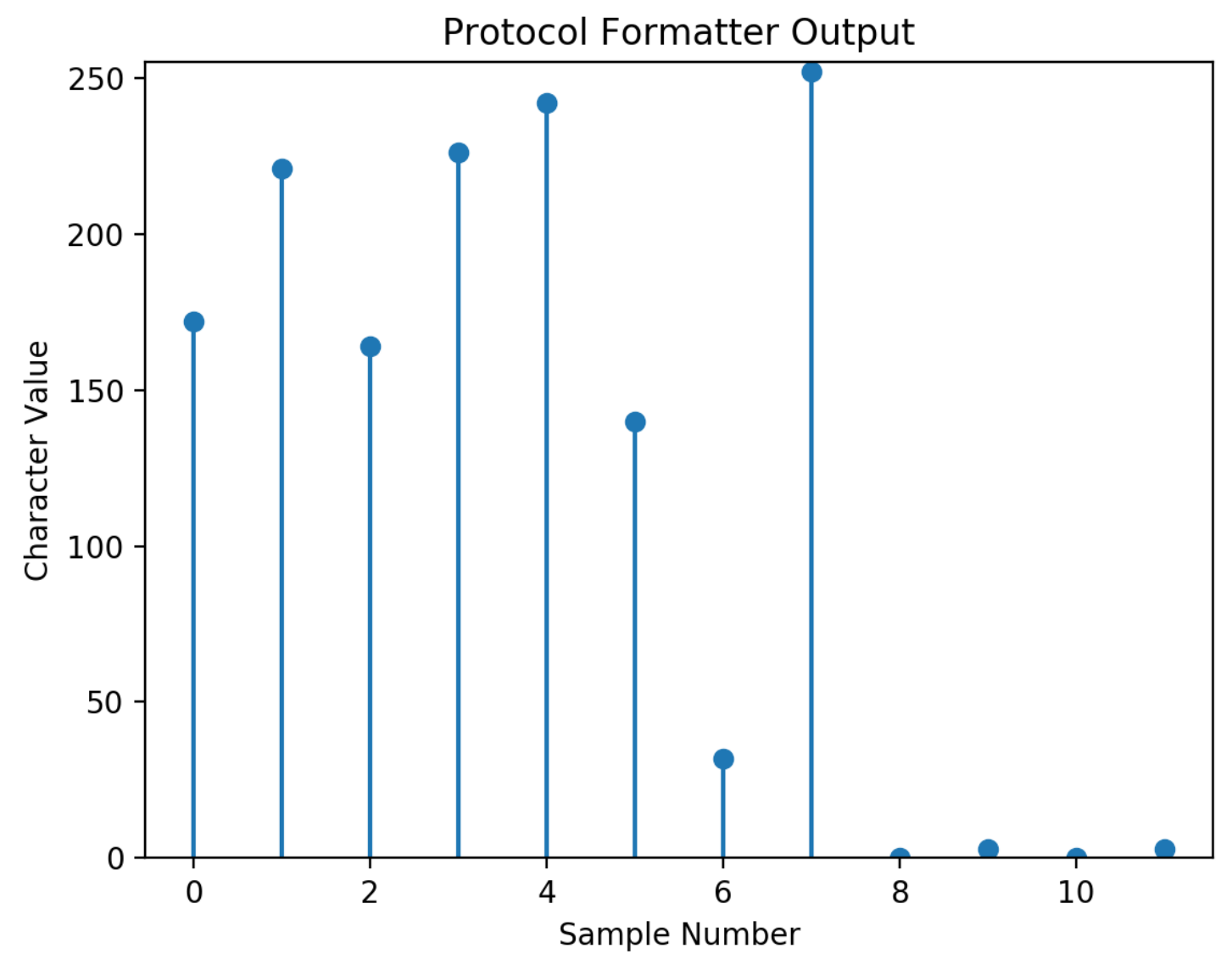




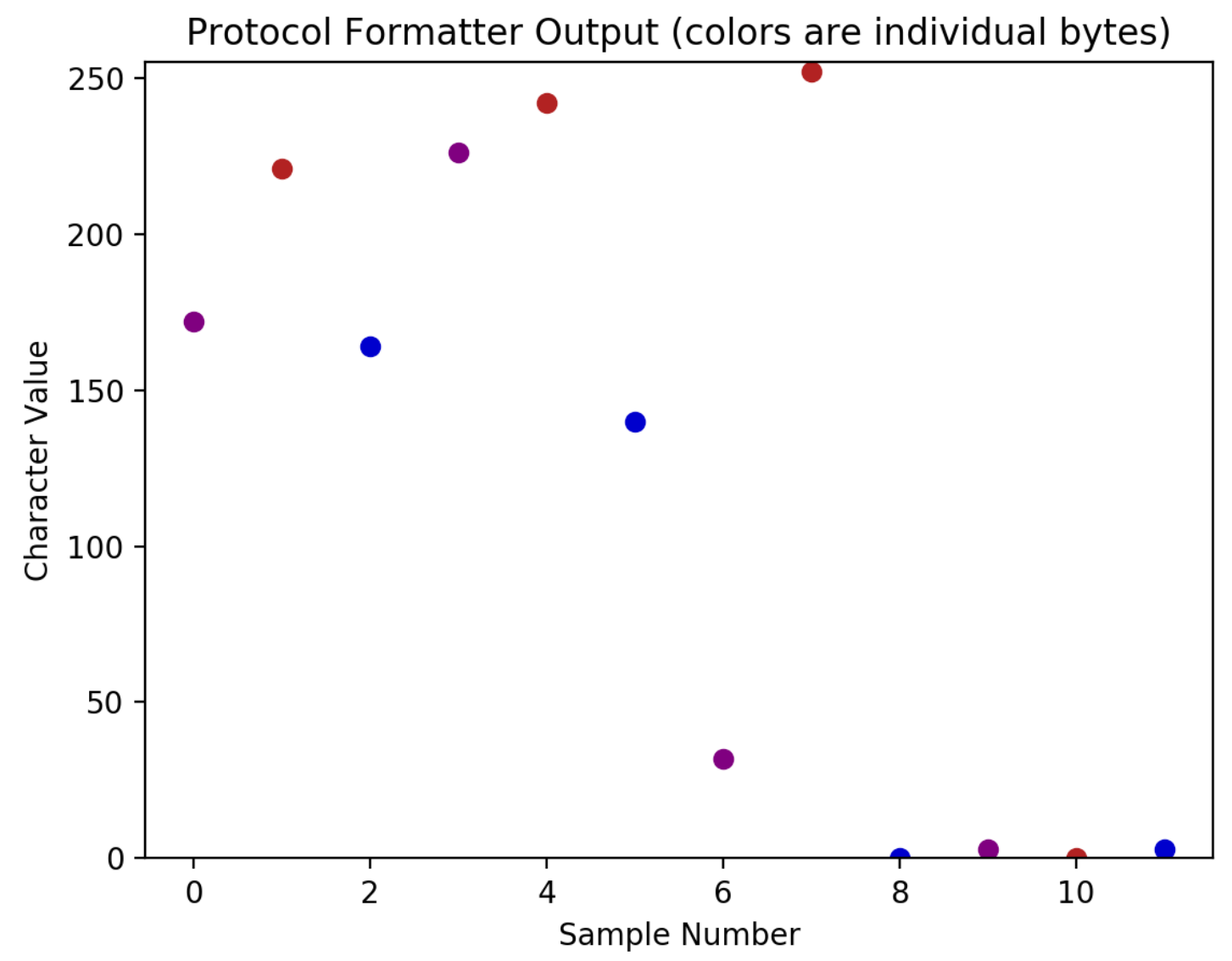

The protocol formatter block creates a tagged stream of 1's and 0's that will be attached to the payload. In our case, we use the default preamble of '1010010011110010' and access code of ' 1010110011011101101001001110001011110010100011000010000011111100 ', which is displayed above as bytes. 


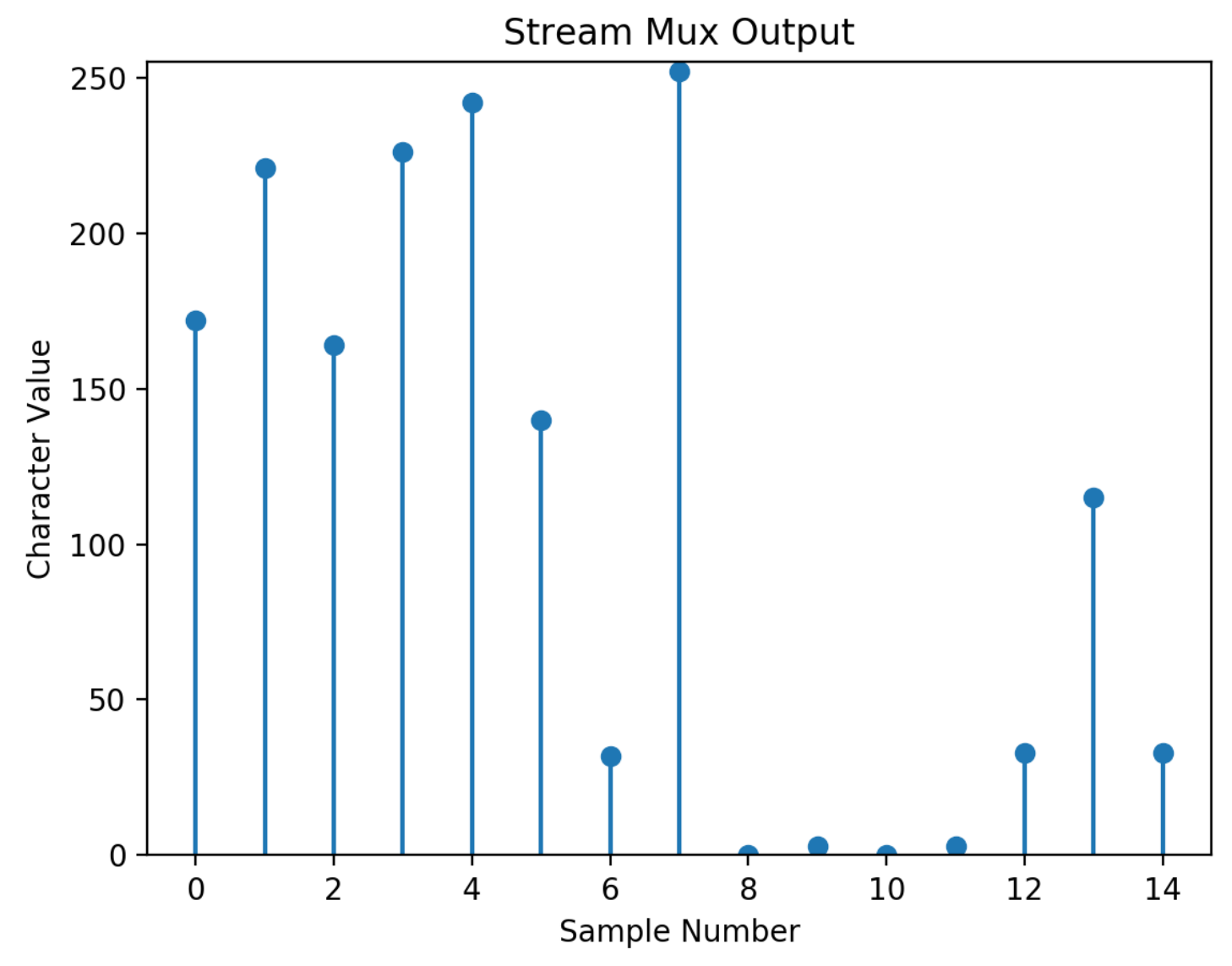




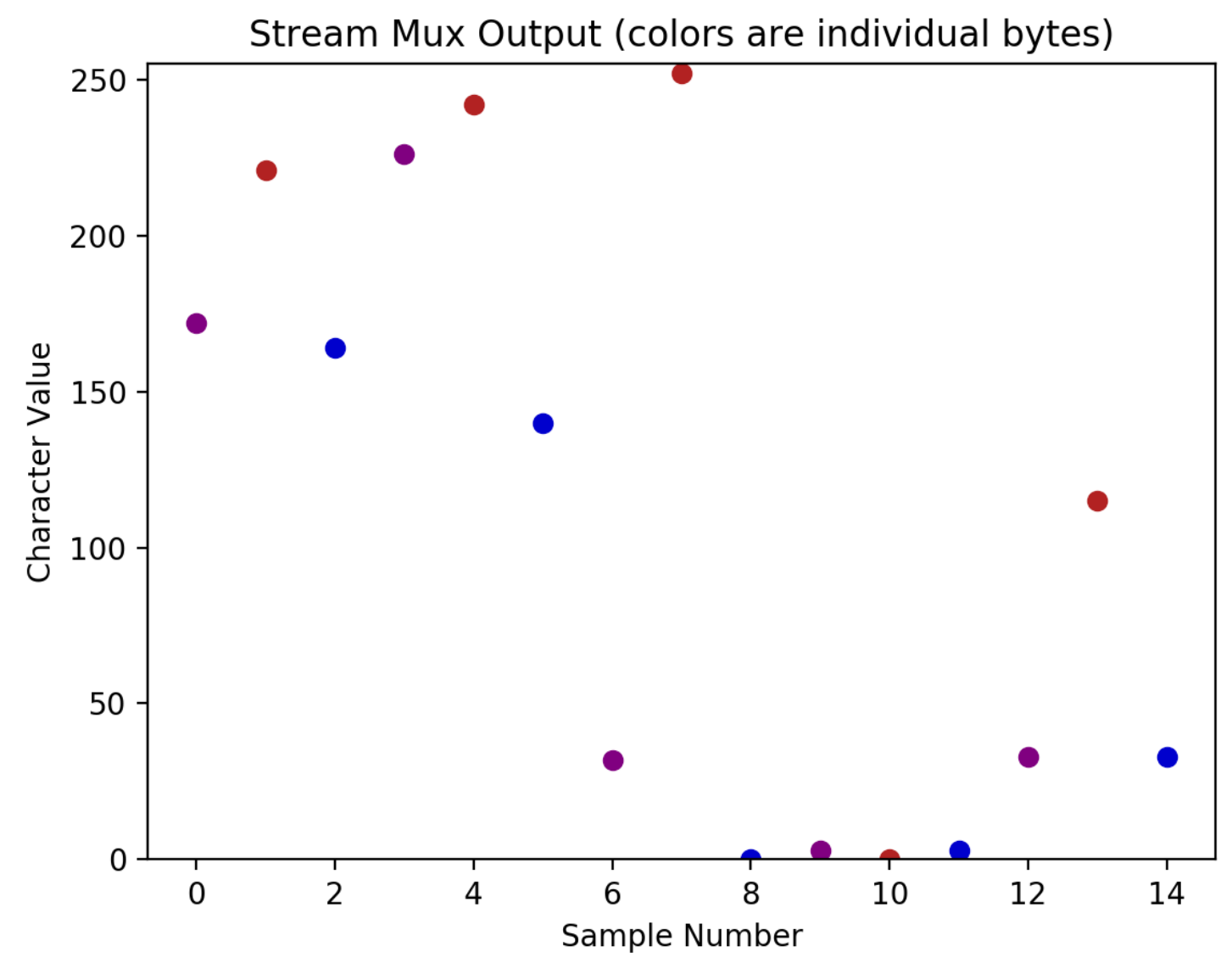

Above we can see how the header file is combined with the payload. We first see the attached preamble in the form of bytes. The first 12 bytes are from the protocol formatter while the last 3 are from the file source. Specifically, we can see that bytes 12, 13, 14 match the file source. 


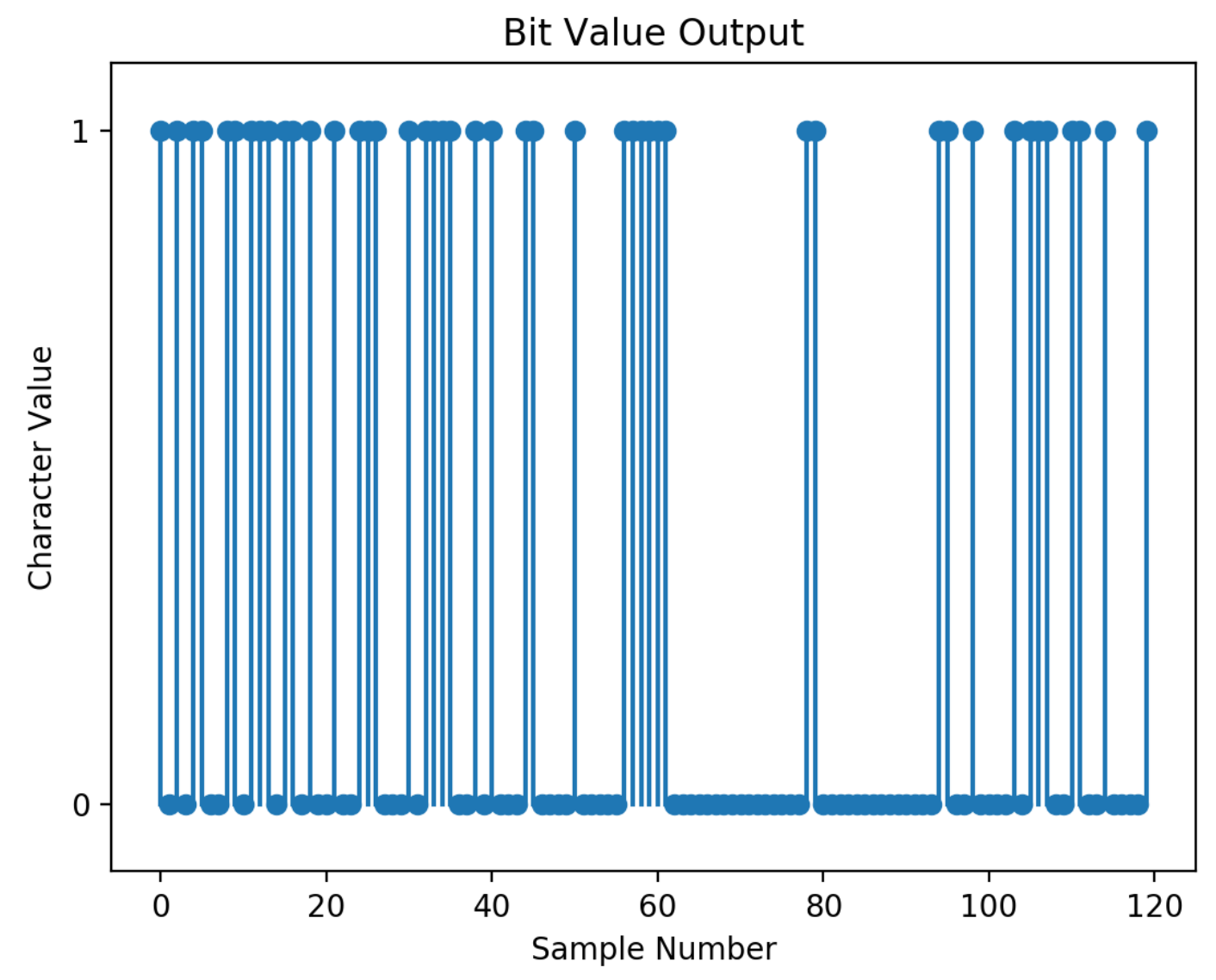


Bit Value Output (colors are individual bytes, dots are individual bits)

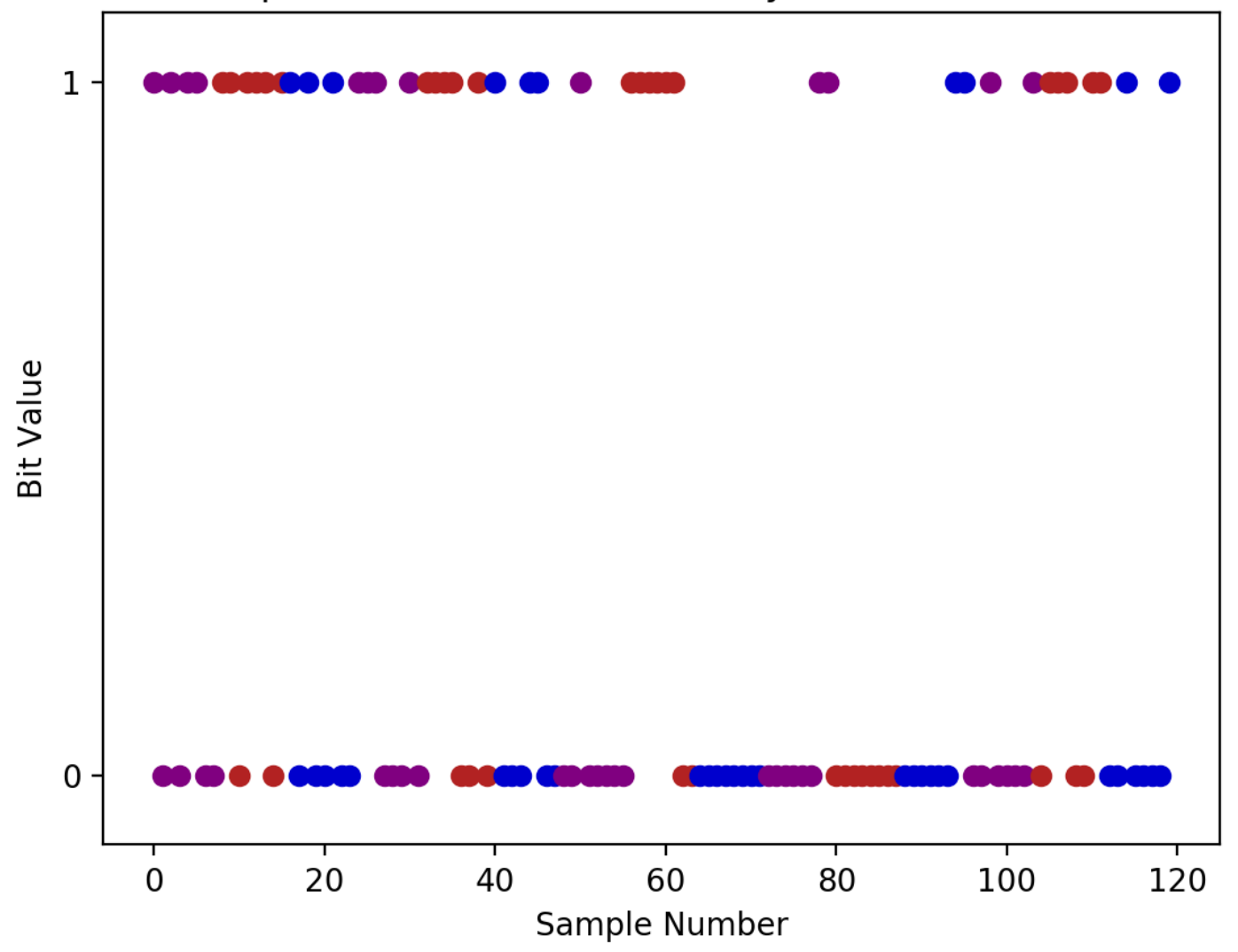

We can now see how after the stream mux, we unpack the individual bytes into 8 bits each. The individual bytes are displayed above with colors corresponding to each byte. There are 15 bytes in total for the packet, meaning that we are now sending 120 samples through the system $\left(15^{\star} 8=120\right)$ 


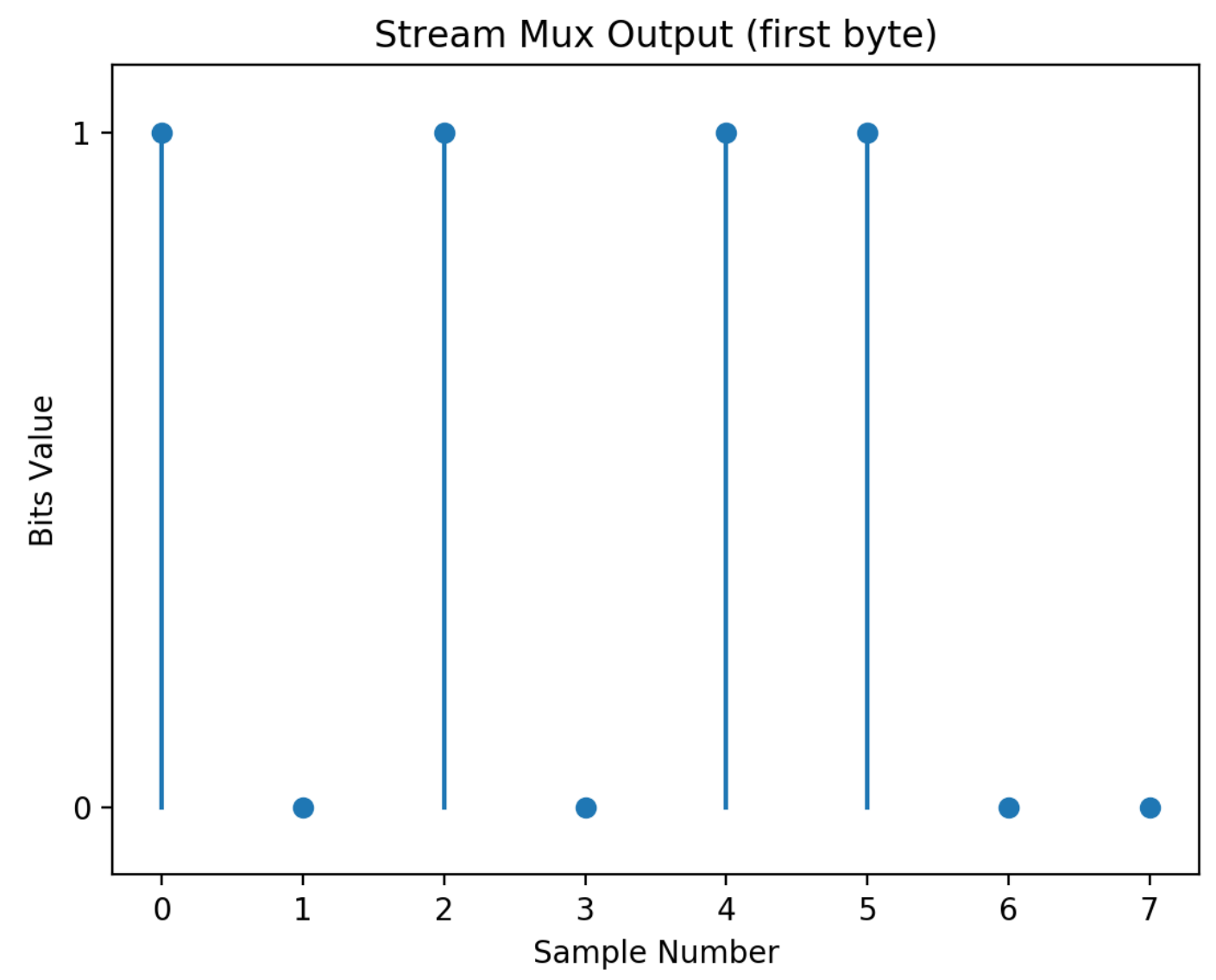




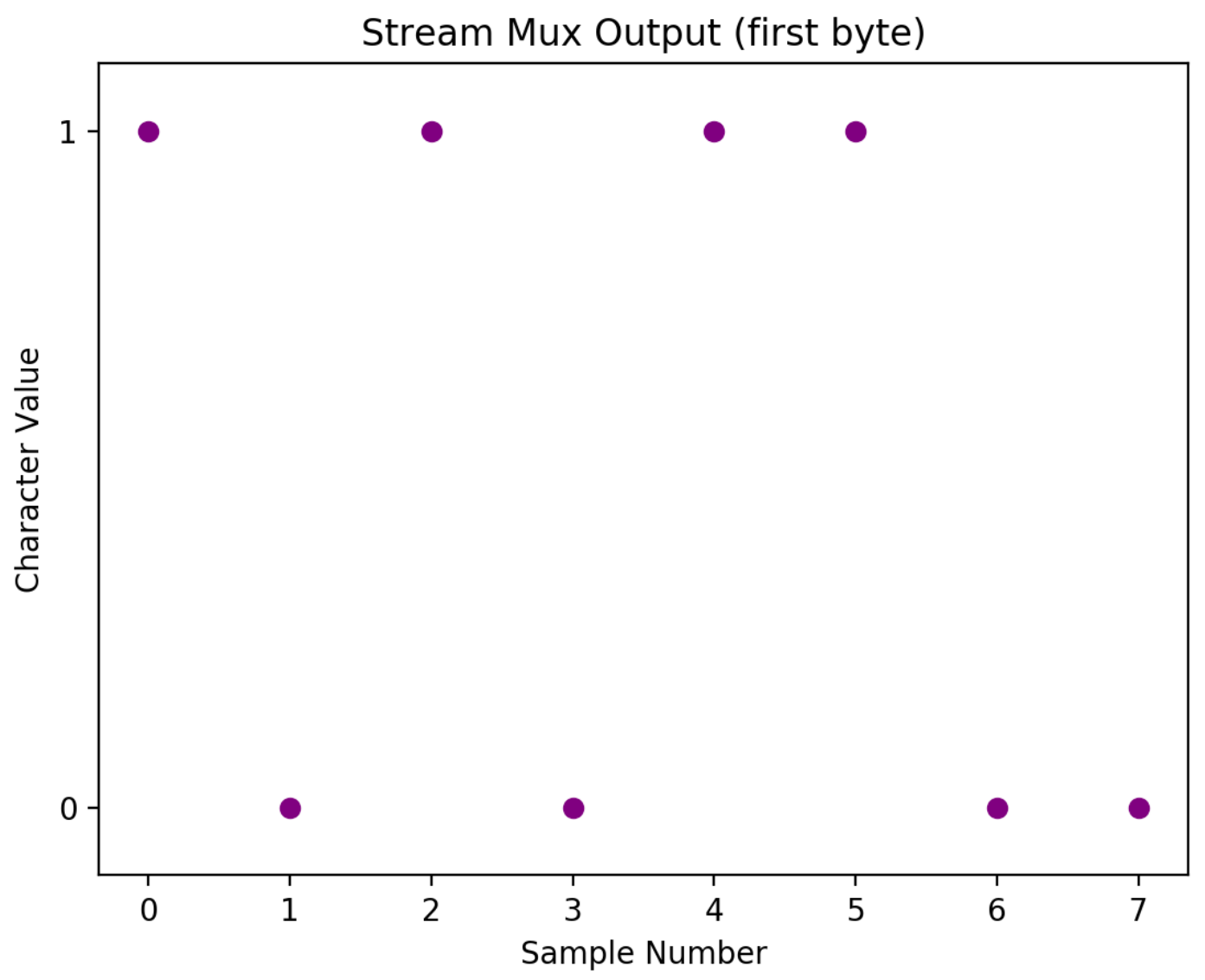

Above is a zoomed in view of the first byte in the stream. We can see that it does in fact correspond to the character value of 172 , since $10101100=\left(1 \times 2^{7}\right)+\left(0 \times 2^{6}\right)+\left(1 \times 2^{5}\right)+(0 \times$ $\left.2^{4}\right)+\left(1 \times 2^{3}\right)+\left(1 \times 2^{2}\right)+\left(0 \times 2^{1}\right)+\left(0 \times 2^{0}\right)=172$. 


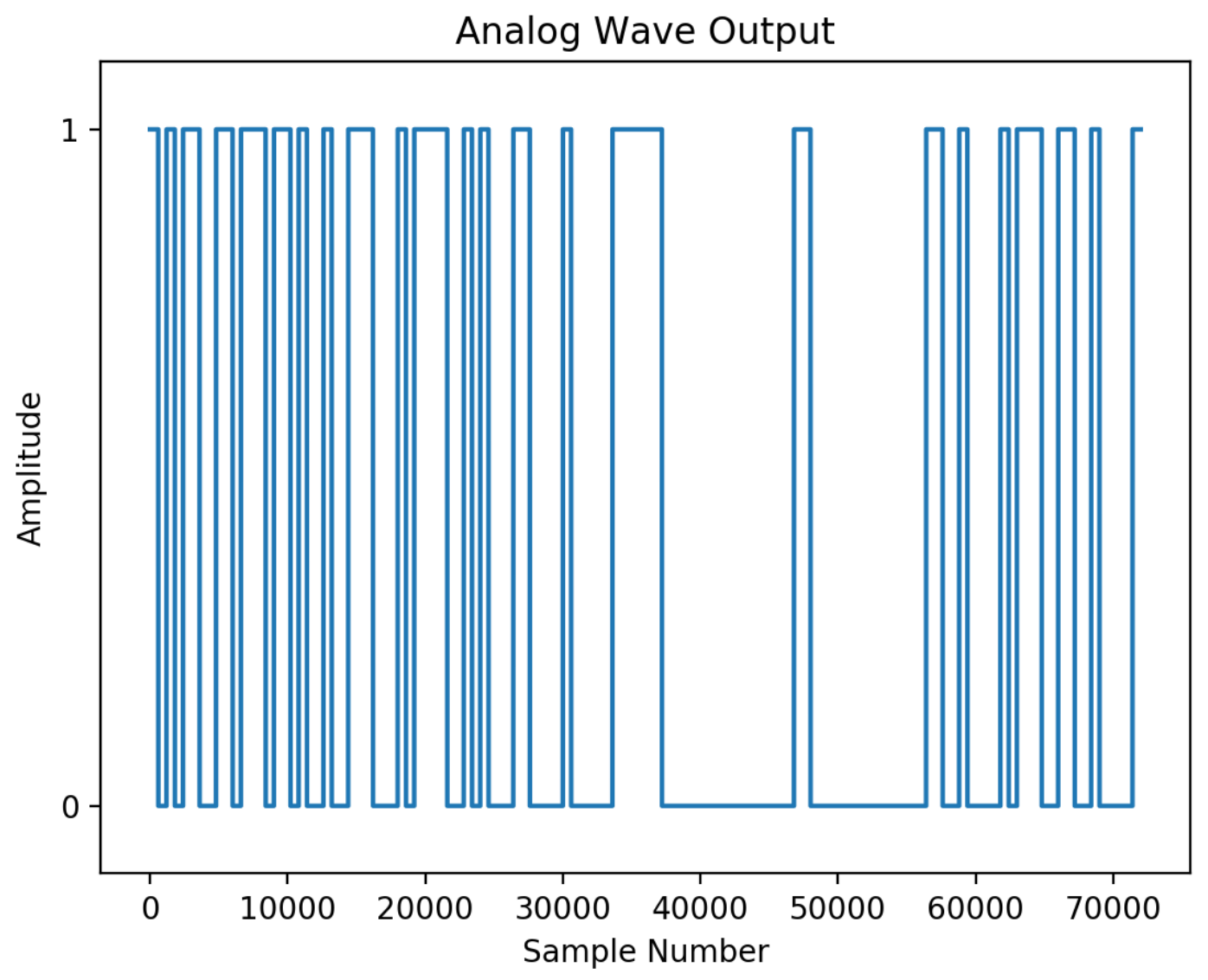




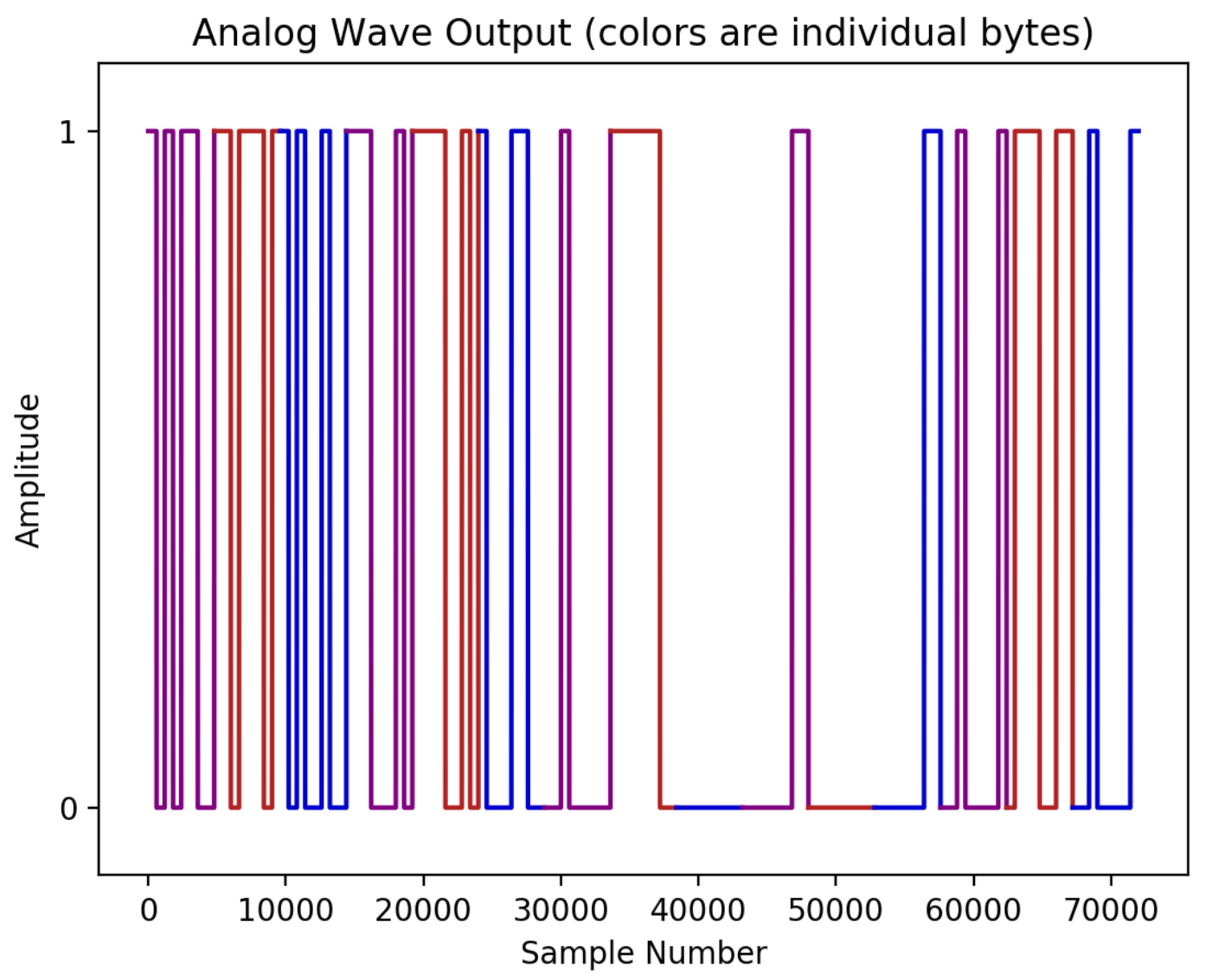

Above we see what happens to the information after the rational resampler and moving average block. Each bit is interpolated to create 600 bits after it, which is why the total number of samples goes from 120 in the figure with the data displayed as bits, to 72000 in the above figures $\left(120^{*} 600=72000\right)$. In both graphs, we can can see how the signal gets converted from digital to analog, making the latter into a square wave. Below is an FFT of the analog wave output. 


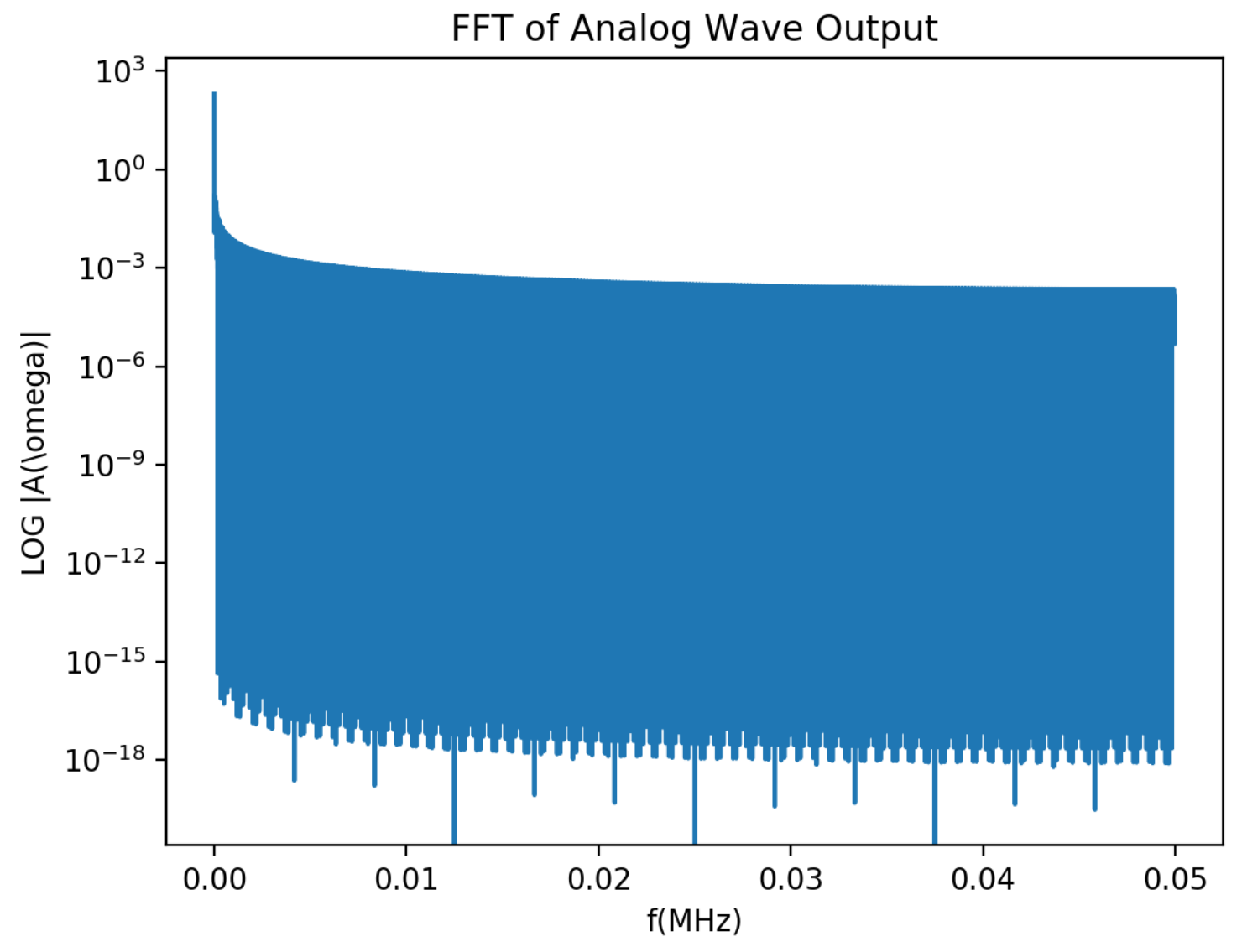




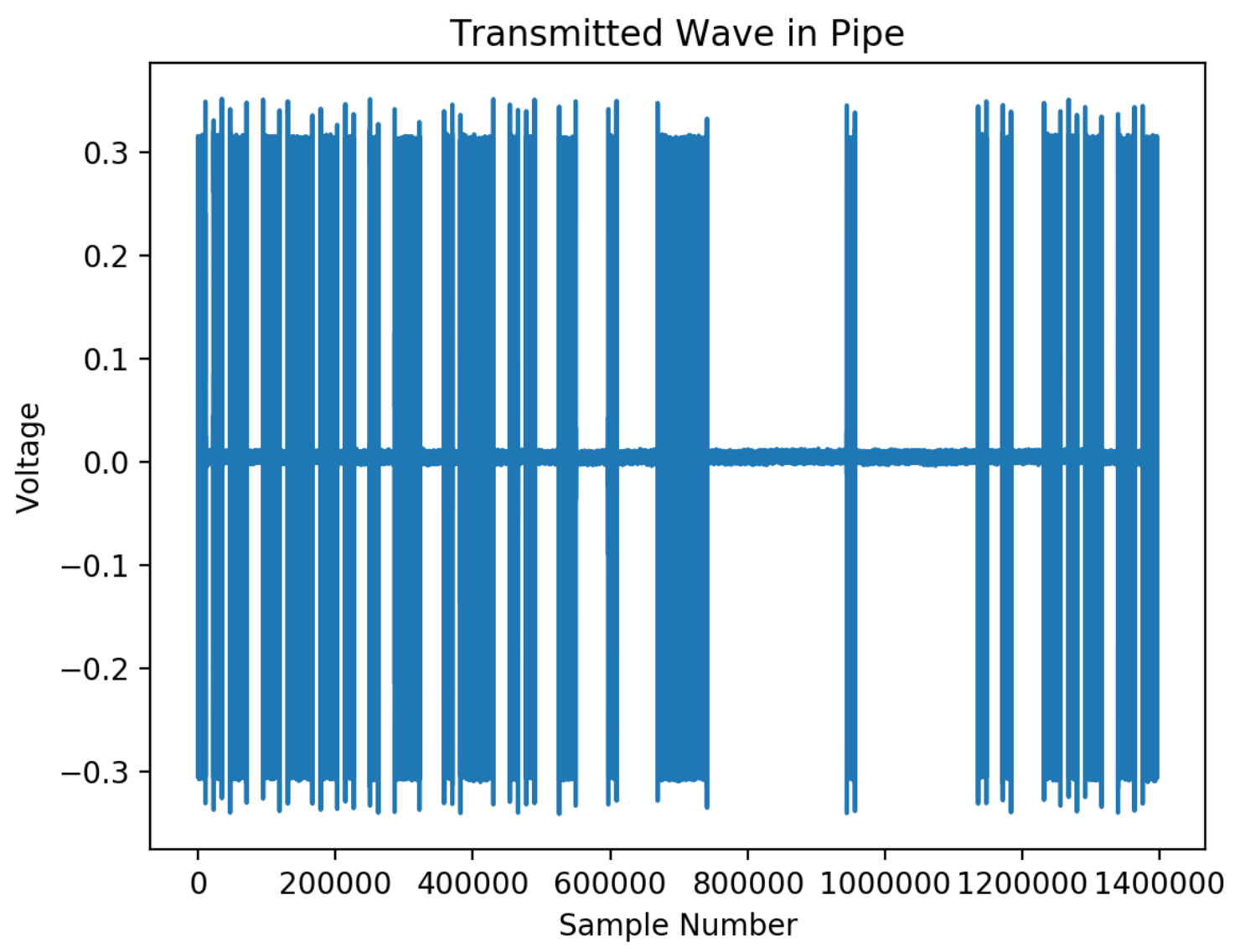




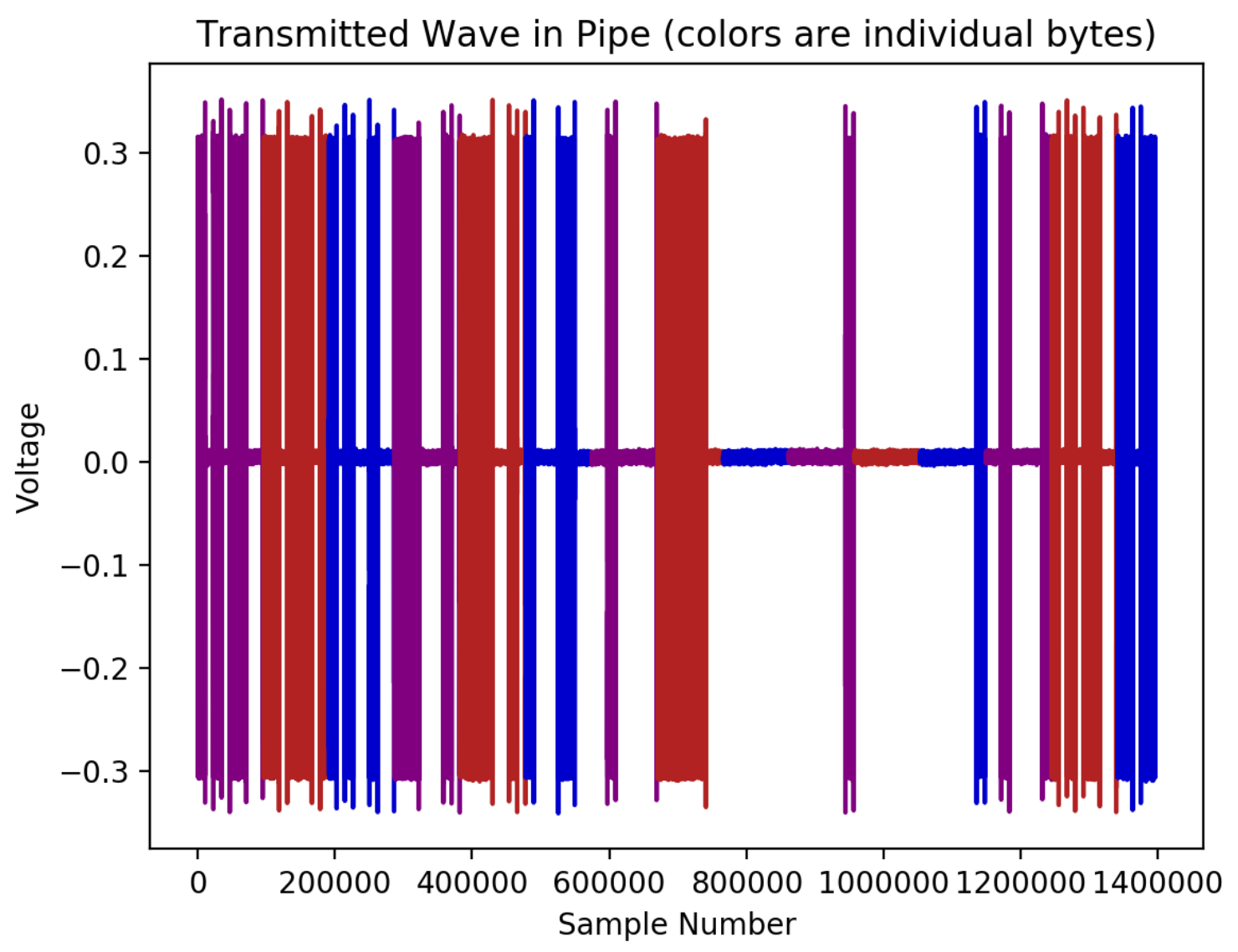

The two above figures are taken from the oscilloscope at a sampling rate of $25 \mathrm{Ms} / \mathrm{s}$, which is much higher than GNURadio's rate of $100 \mathrm{ks} / \mathrm{s}$, which is why the number of samples for the same signals is 250 times higher than in GNURadio $(250 * 100,000=25,000,000)$. The individual bytes from the square wave are all translated into a signal with amplitude ranging from -0.3 to 0.3 volts. Note that in our setup we pass this signal into a $50 \mathrm{~dB}$ amplifier, the transducer actually feels a voltage of about 95 volts. We can see that Red Pitaya introduces ringing into the system on every on/off voltage high/low. This kind of behavior is why we chose to use binary ASK over quad ASK, since this kind of instability only lends itself to on or off keying. 


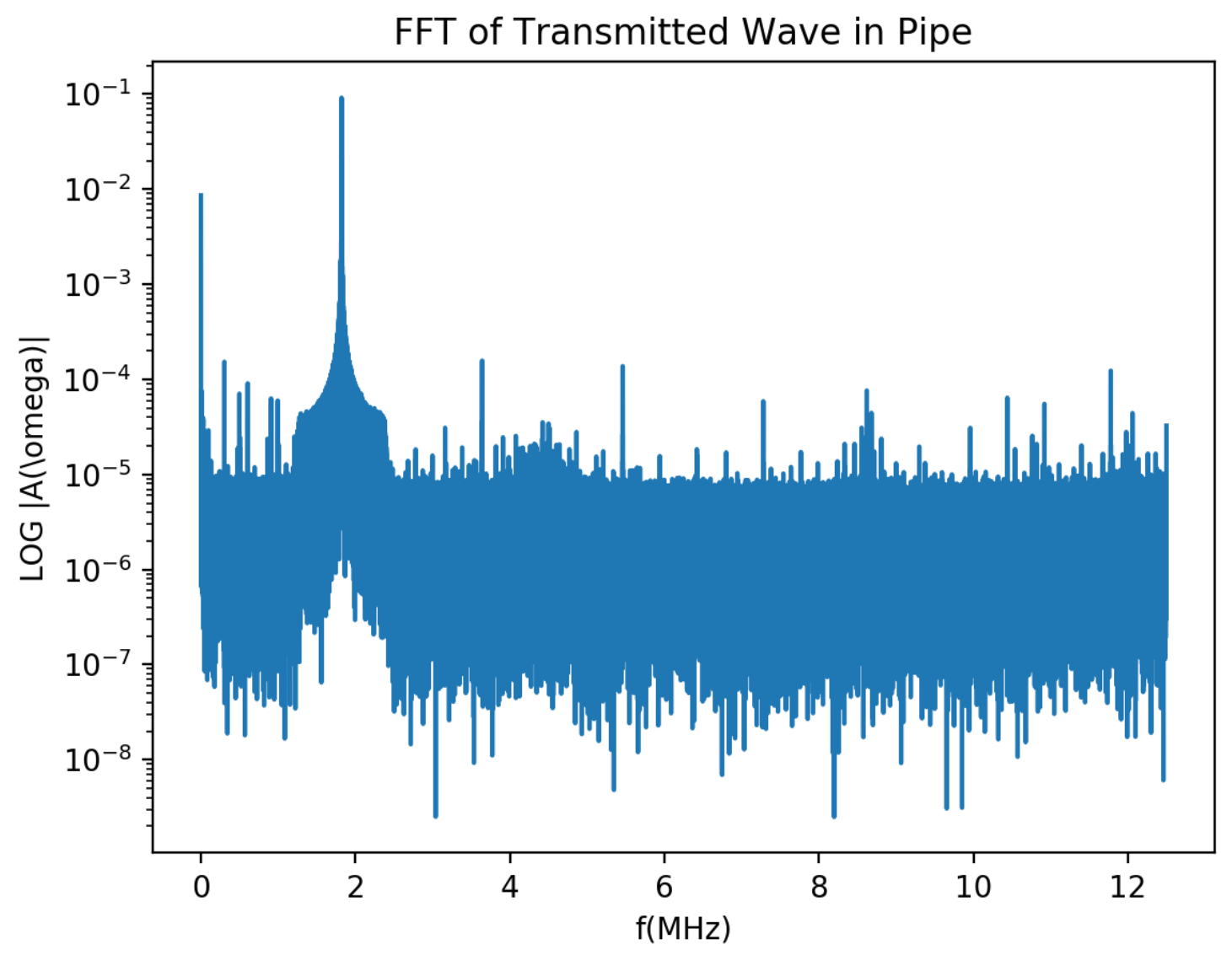

Above is an FFT of the transmitted signal. Compared to the original signal, we see that the frequency response of the square wave is still seen on the lower end of the spectrum, and we can also clearly see the carrier frequency centered at $1.8 \mathrm{MHz}$. We can see that the frequency response of the carrier frequency is stronger than the frequency response of the base band. 


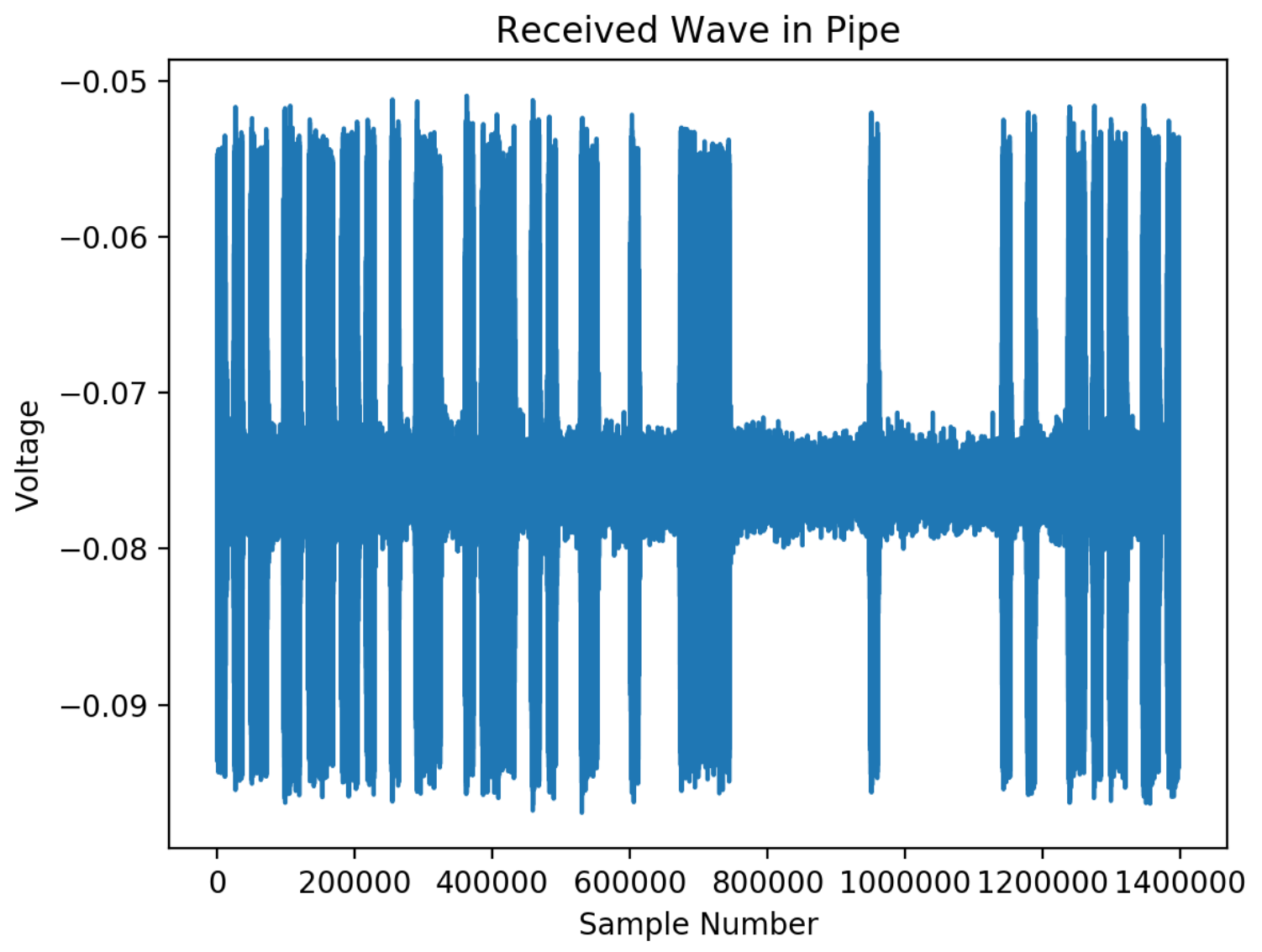




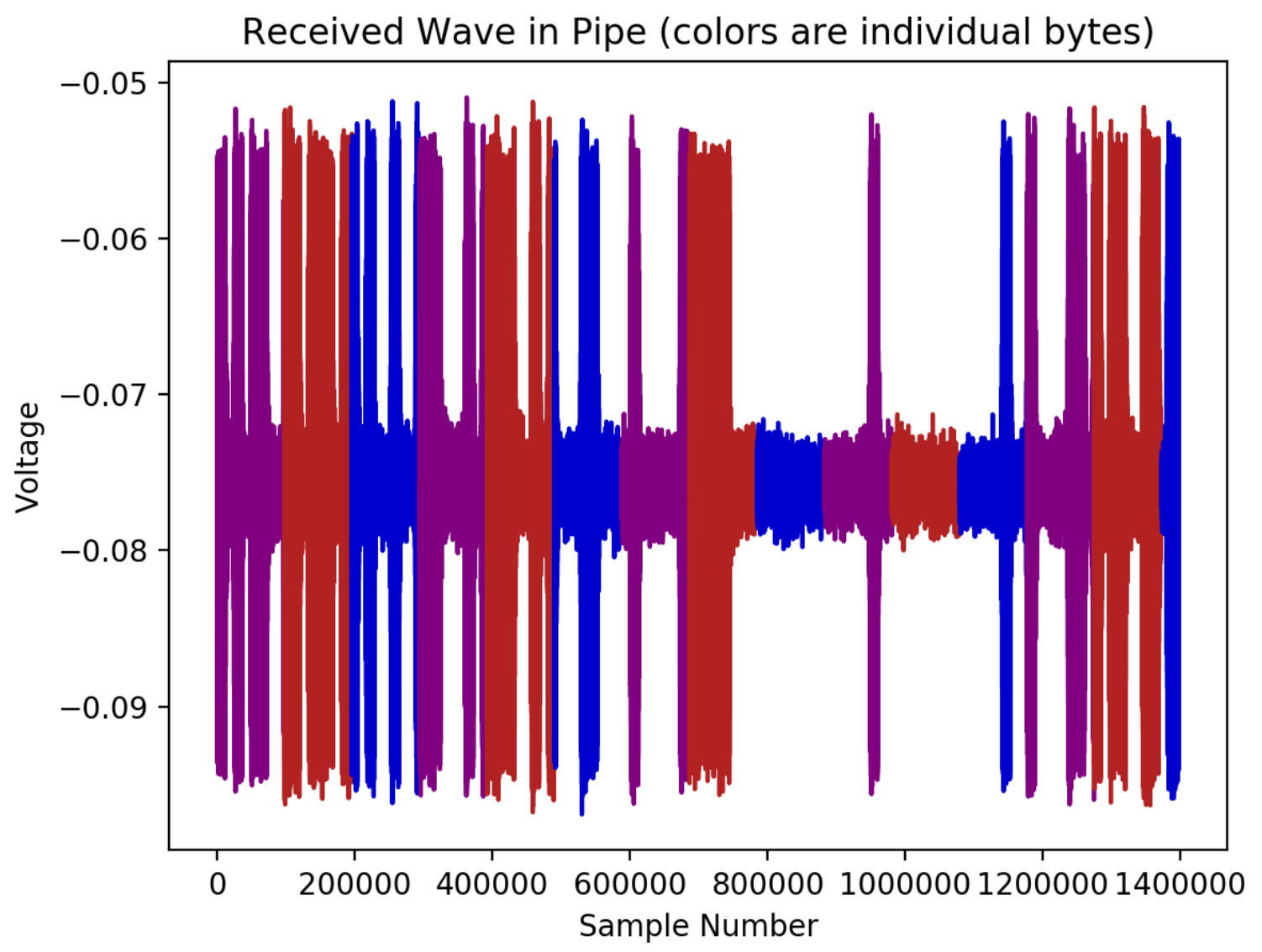

Above we are again viewing oscilloscope data, which is this time connected to the output of the low noise amplifier placed after the receiving transducer. We can see that the signal, even with the use of two amplifiers, is attenuated by 10 and in addition, a DC offset of -0.075 volts is added to the signal. Compared to the transmitted signal, we can see more distortion along the peaks of the signal, as well as a much larger amount of noise around the DC offset. 


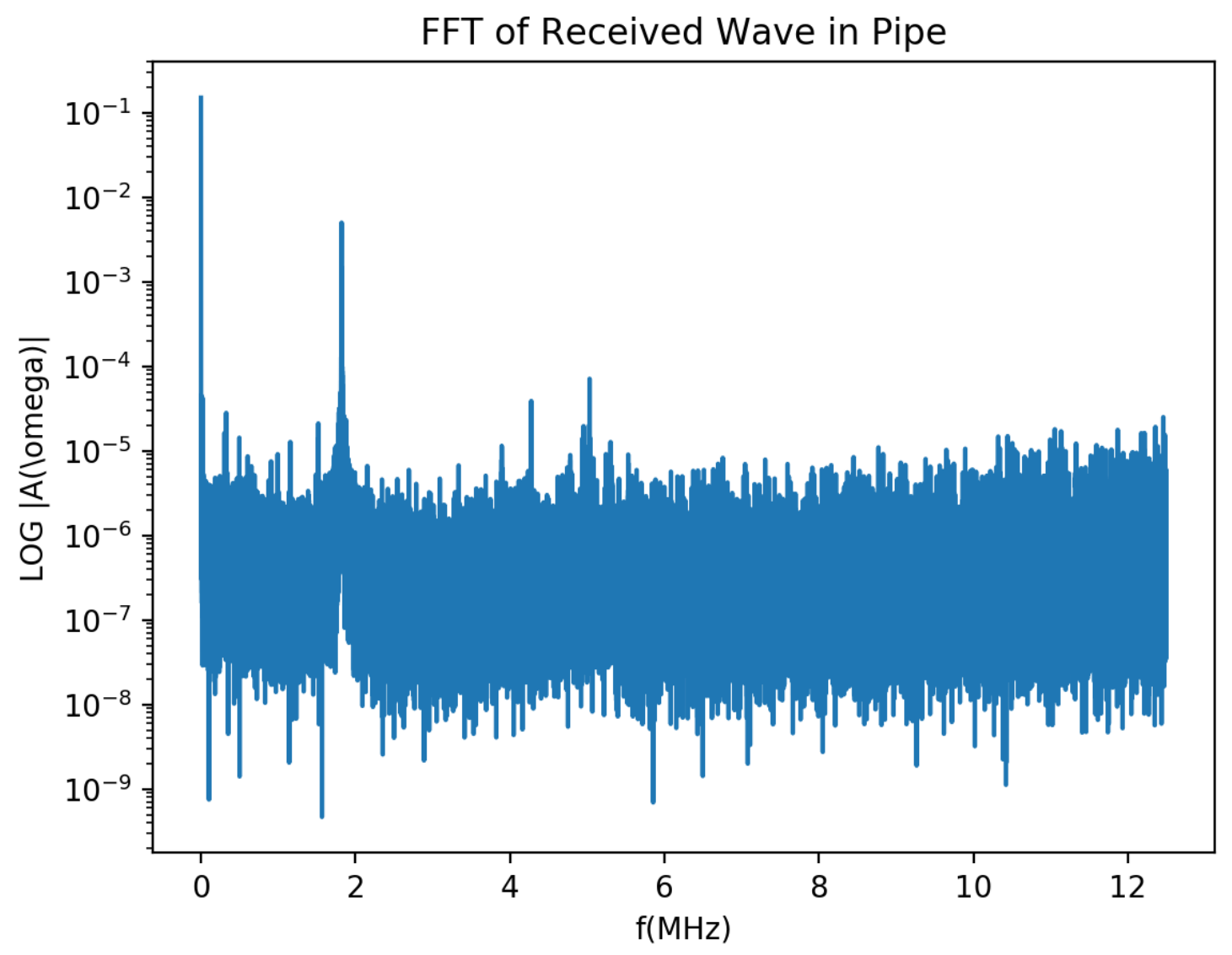

Above is the frequency response of the received waveform. Compared to the transmitted waveform, we can see that the frequency response of the baseband is higher than the frequency response of the carrier frequency. 


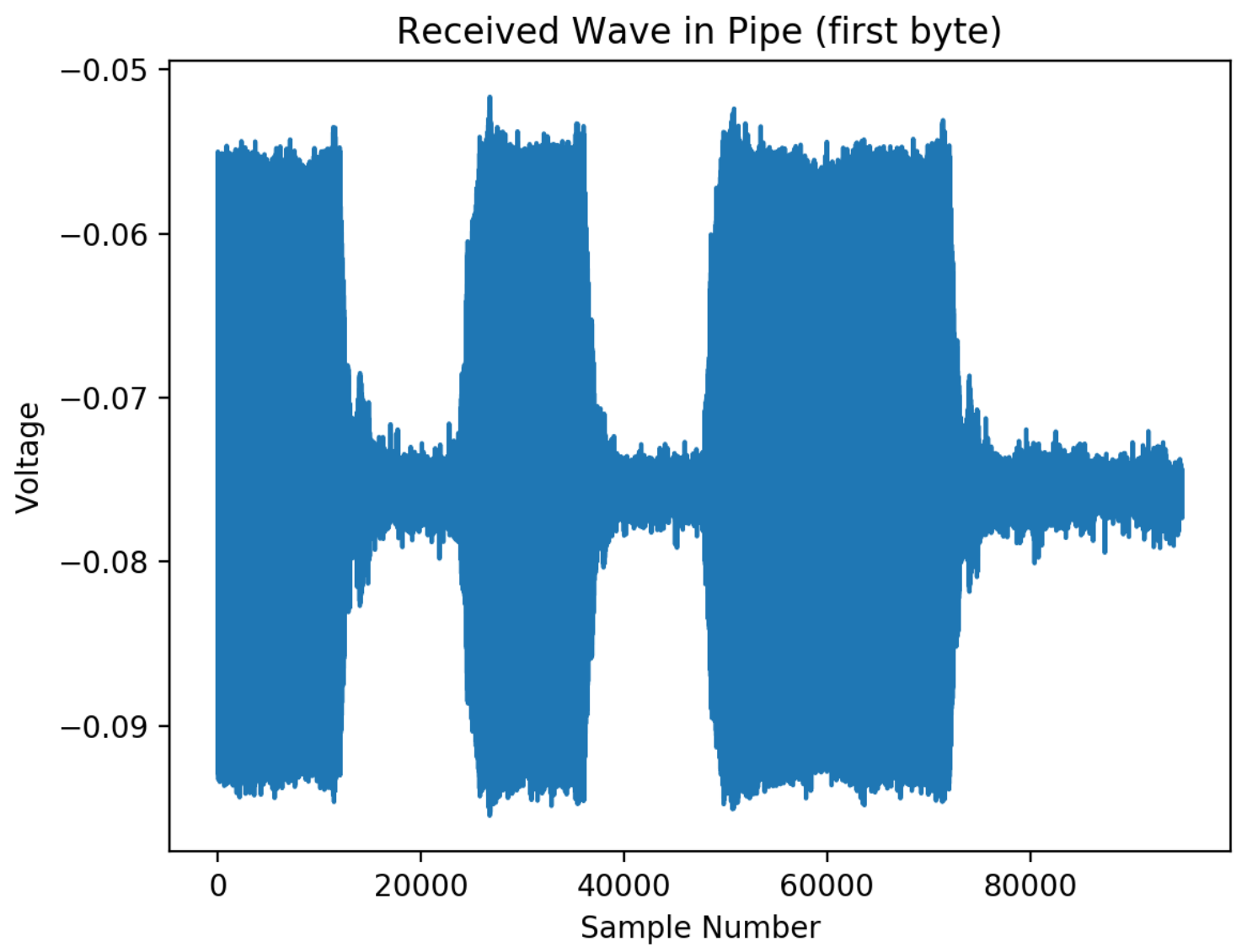




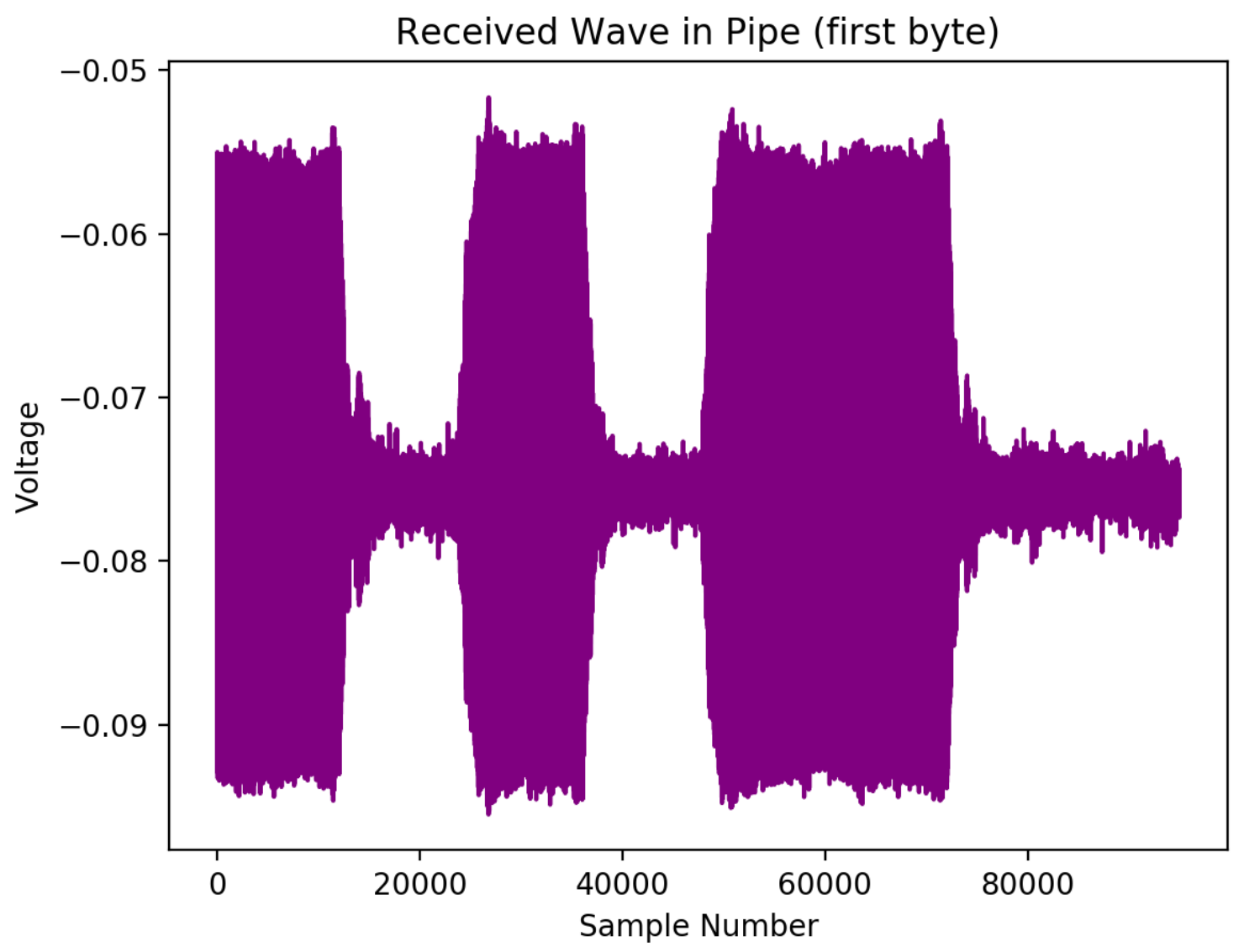

Above we can see the received transmission of the first byte in the string of characters. We see that after the shift keying has been switched to the off position, we still see some ringing from the waveform. 


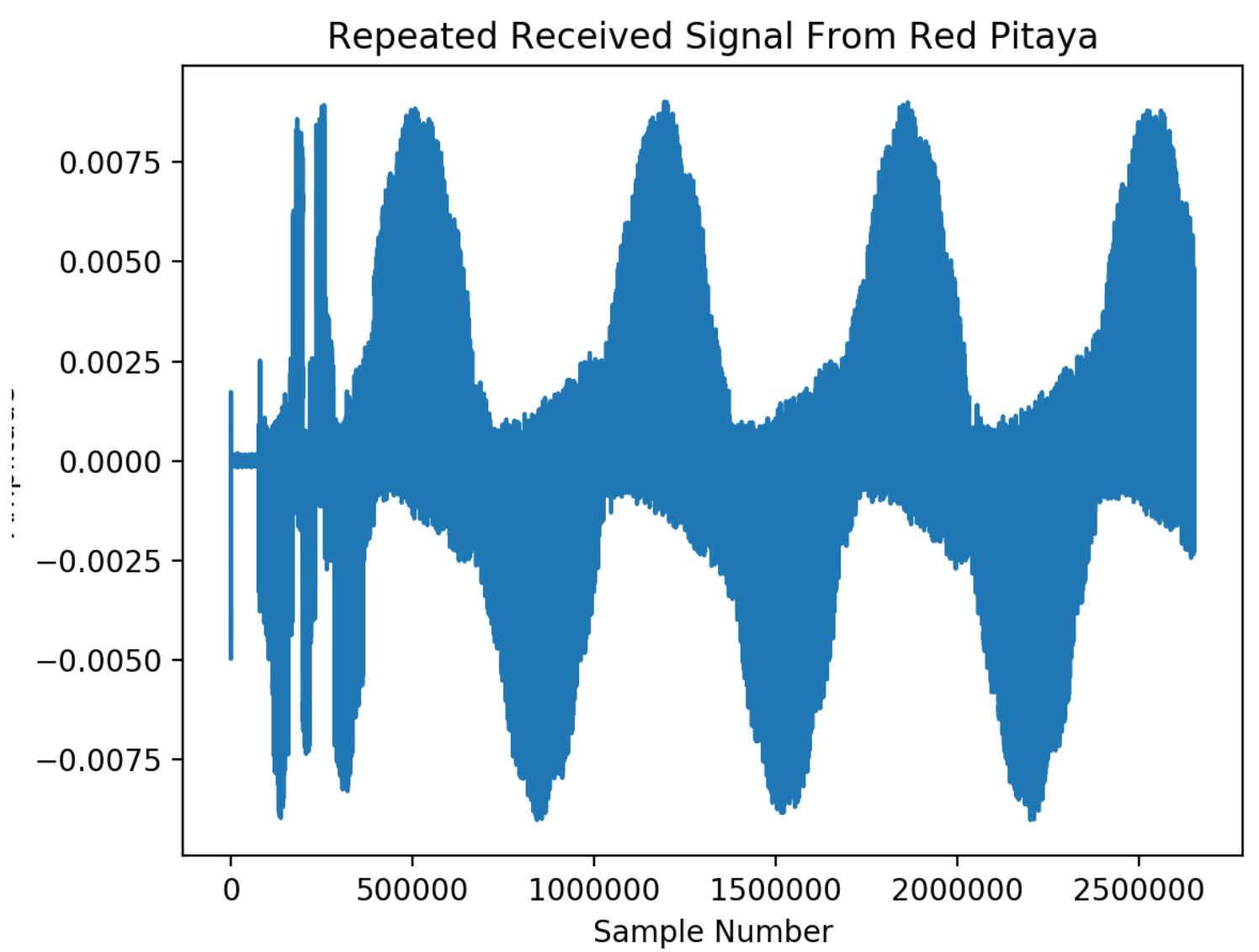

Above is the received signal from red pitaya, displaying the repeated string of characters. We see that at first the system produces information that cannot be decoded (Sample number $<500000$ ), but then proceeds to produce a waveform that is more stable. Since our sample rate is $100000 \mathrm{~S} / \mathrm{s}$, we can therefore conclude that the system has to transmit for 5 seconds before the information can be processed successfully. The overall shape of the incoming signal envelope has a sinusoidal shape, suggesting that there is a phase mismatch between the transmitting Red Pitaya and the receiving Red Pitaya. Below is an FFT of the received signal, which should match that of the transmitted square wave: 


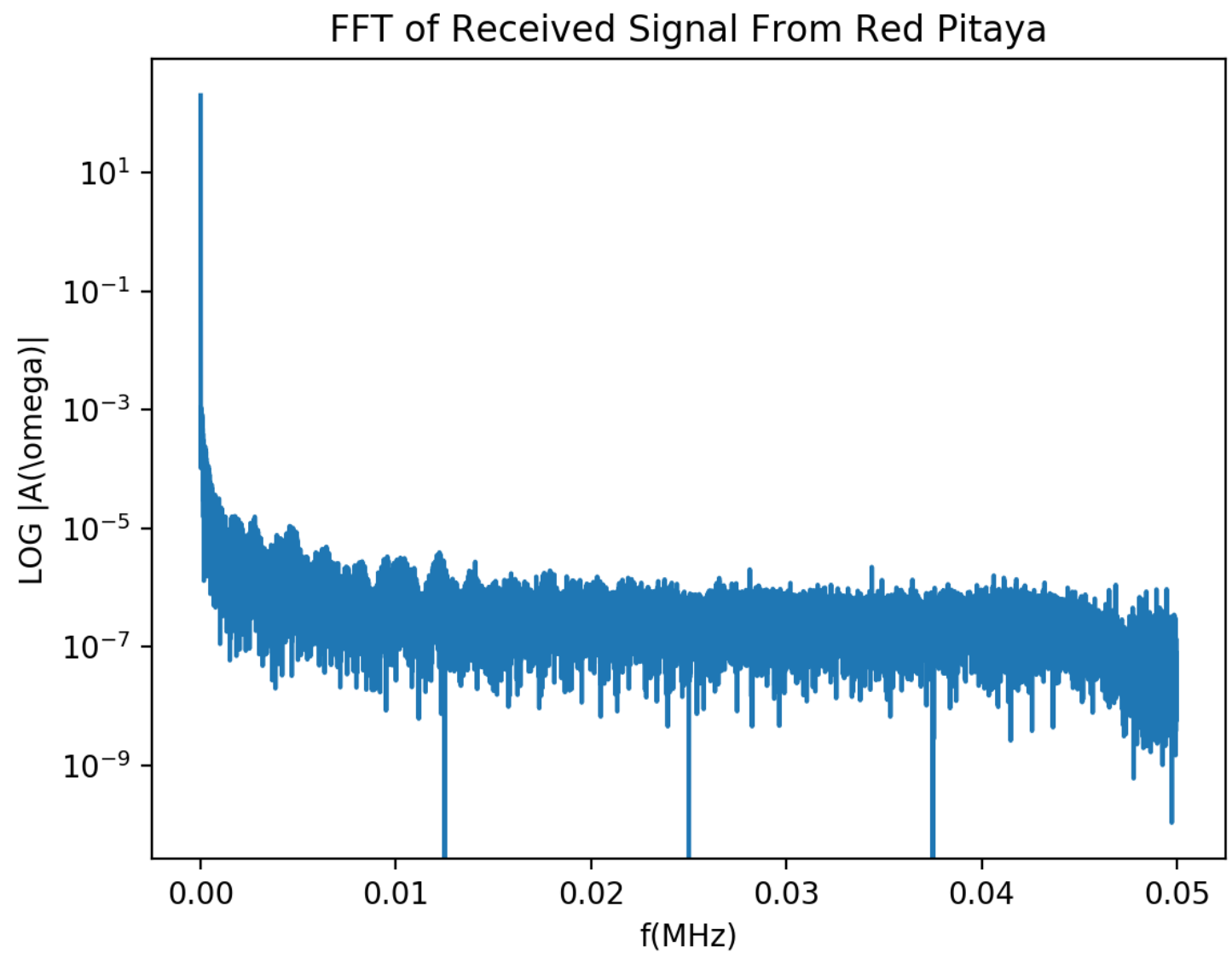

We can see that the frequency roll off is similar to that of the transmitted information, however the frequency response is much less smooth than before. Below we provide a zoomed in version of the character transmission: 


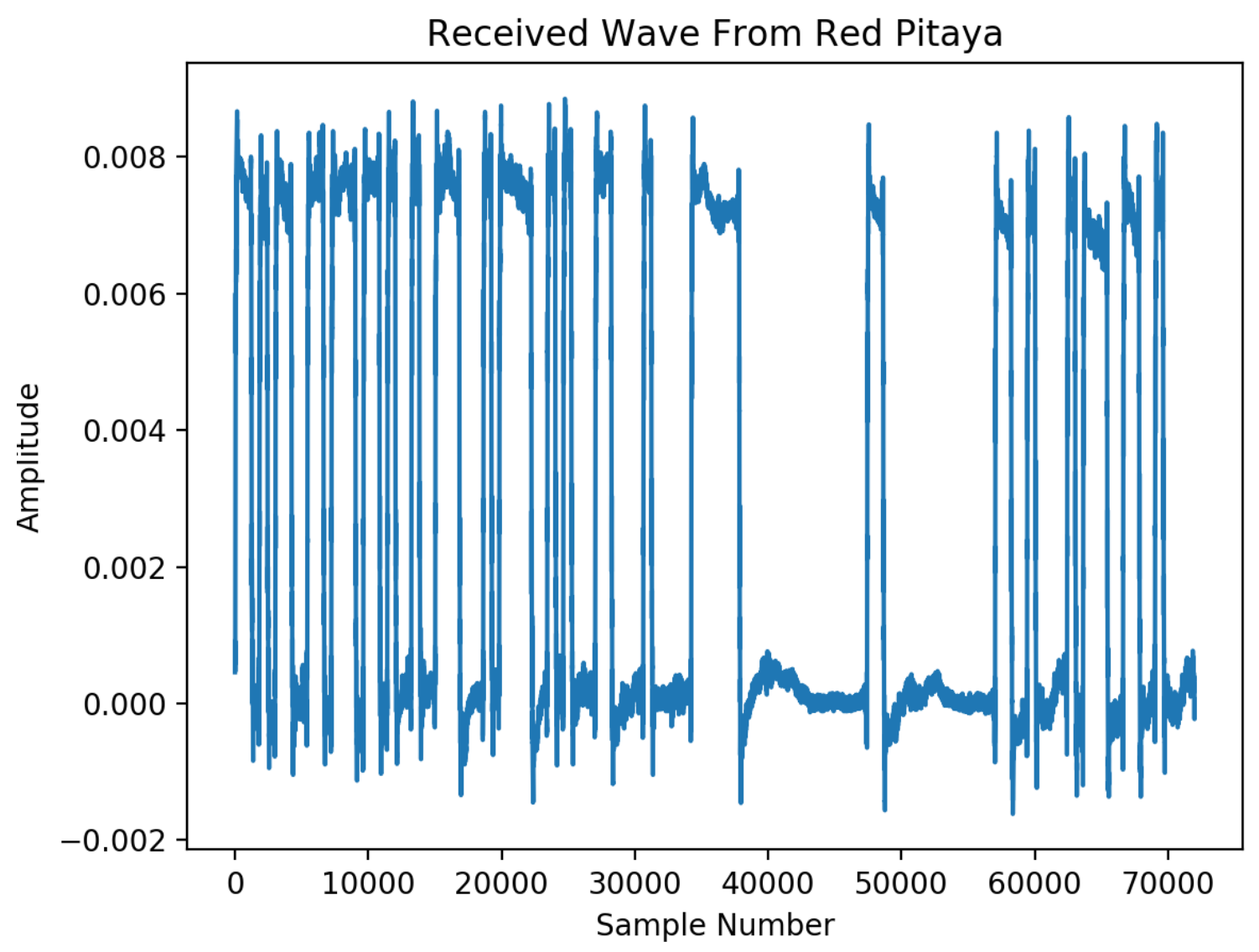




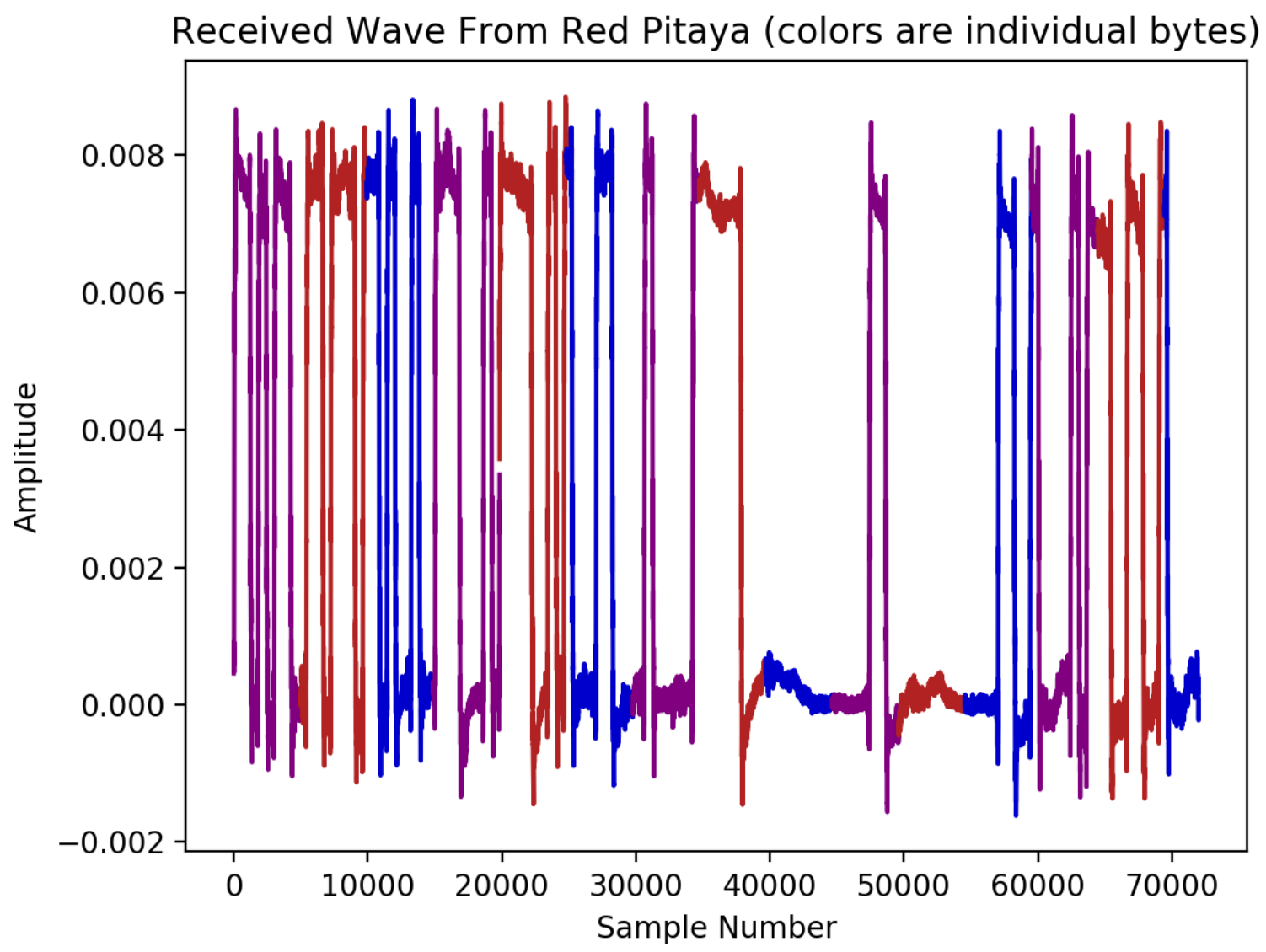

If we compare this plot to the transmitted waveform, we can see that there is much more ringing in this signal compared to the transmitted. This result matches that of the frequency response, as we can see that the imbalanced frequency response makes the square waves less defined. 


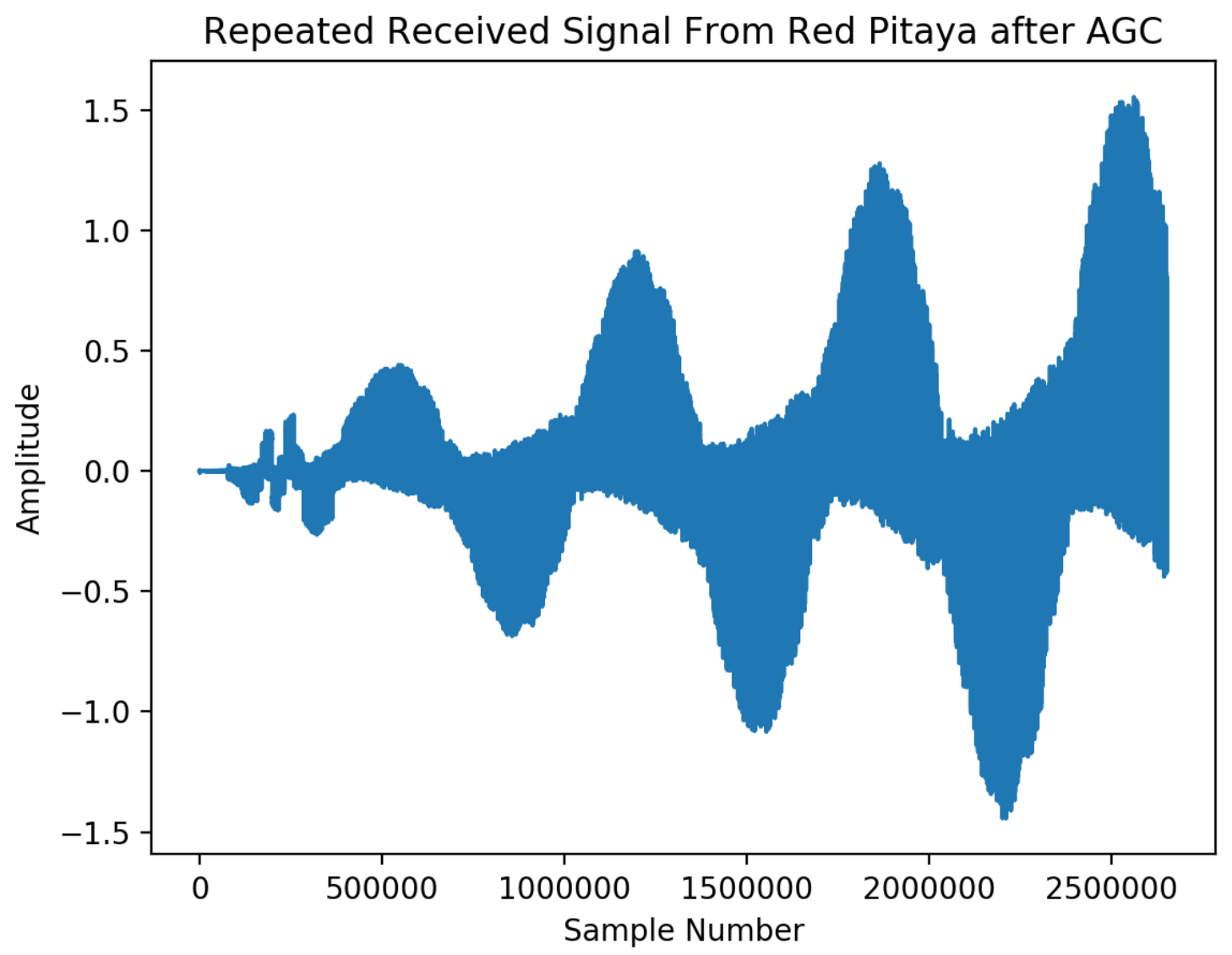

Above is a plot of the signal as that passes through the active gain control. We can see that it has the same shape as that of the signal that exits red pitaya, however the amplitude is increased. This is done to prepare the signal for the threshold section, which needs a greater difference in amplitude. 


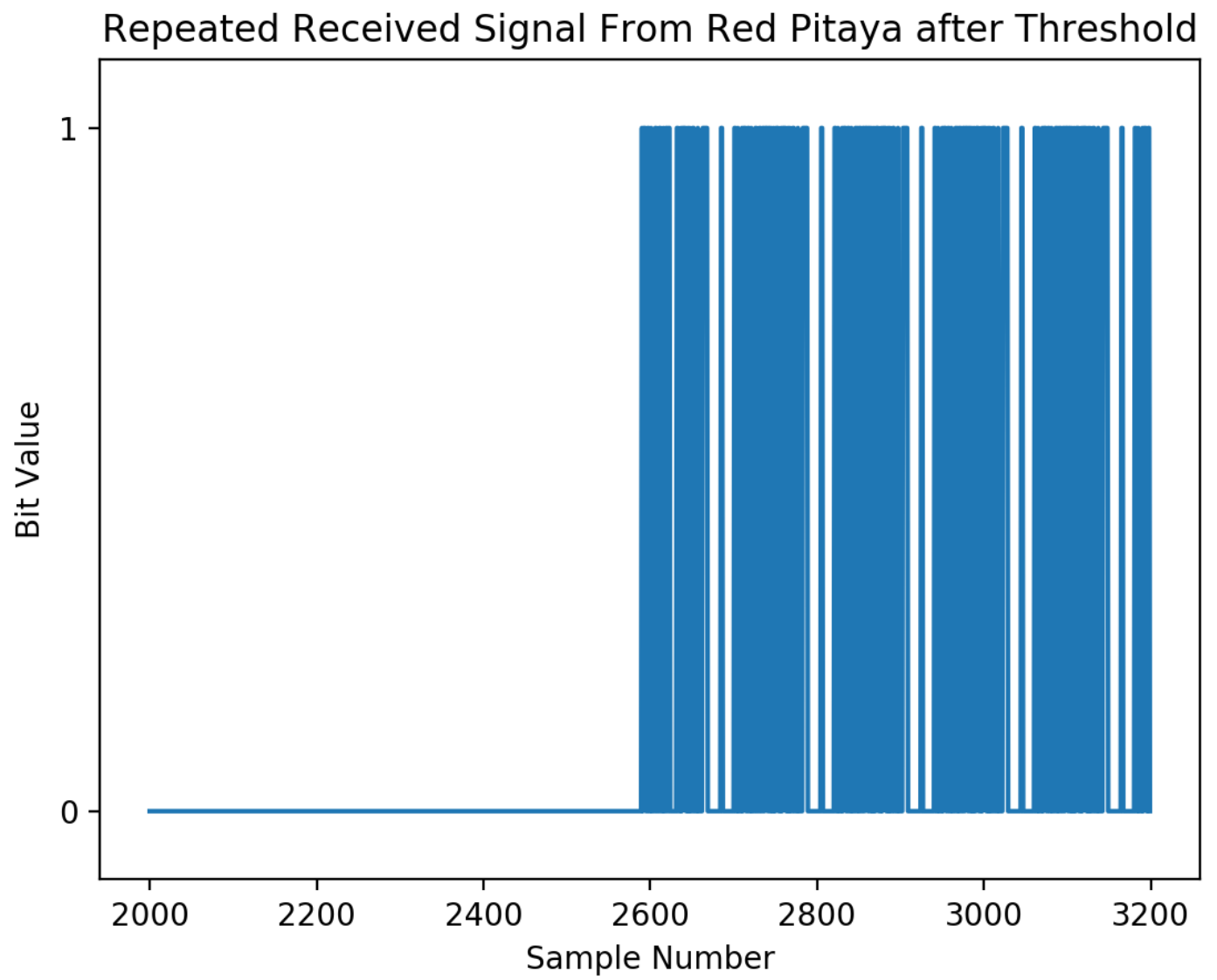

Above is a display of the threshold block after demodulation. We can see that the system can only begin to recognize the bits after a certain number of samples have passed, showing that the active gain control needs time to grow before being demodulated. 


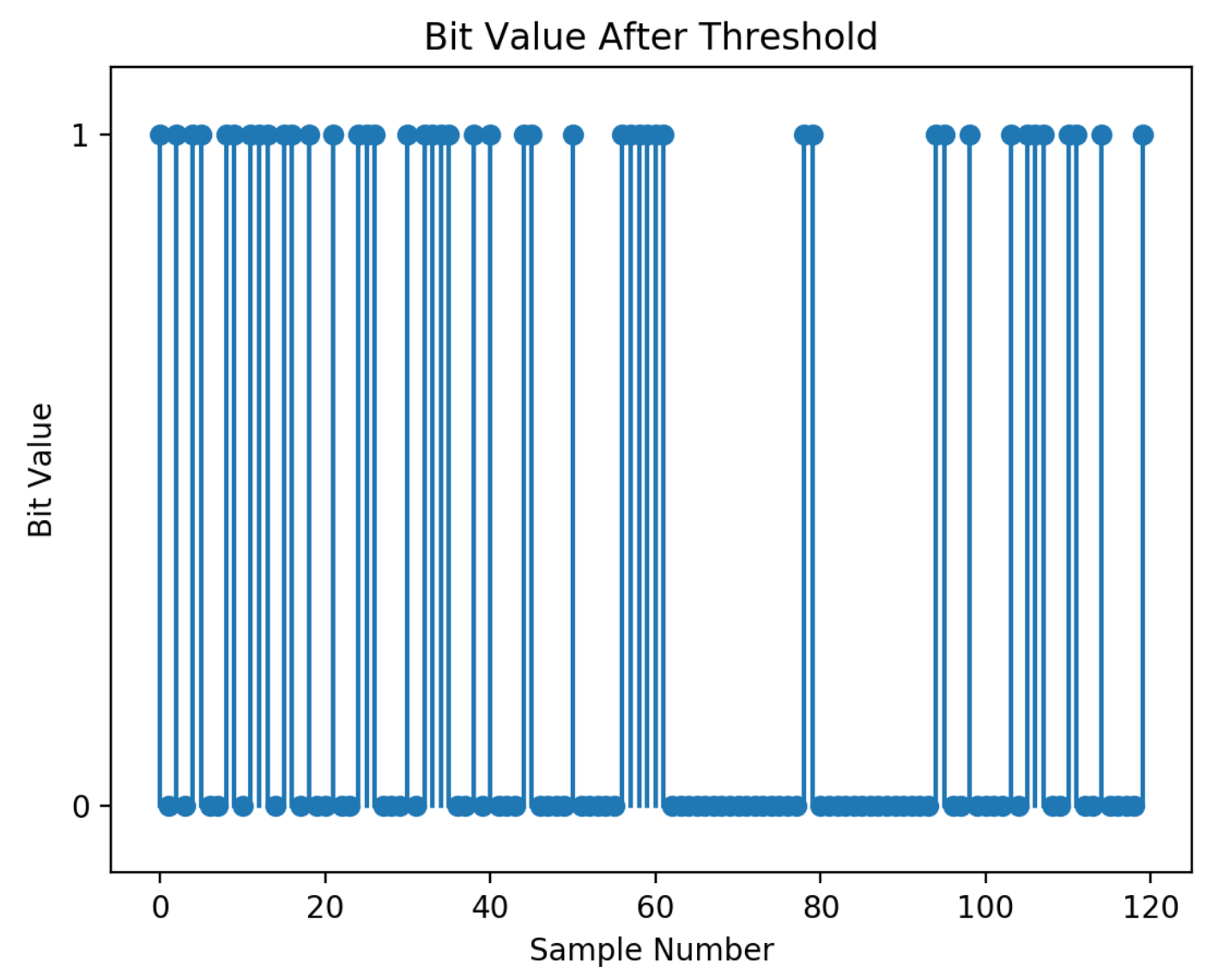




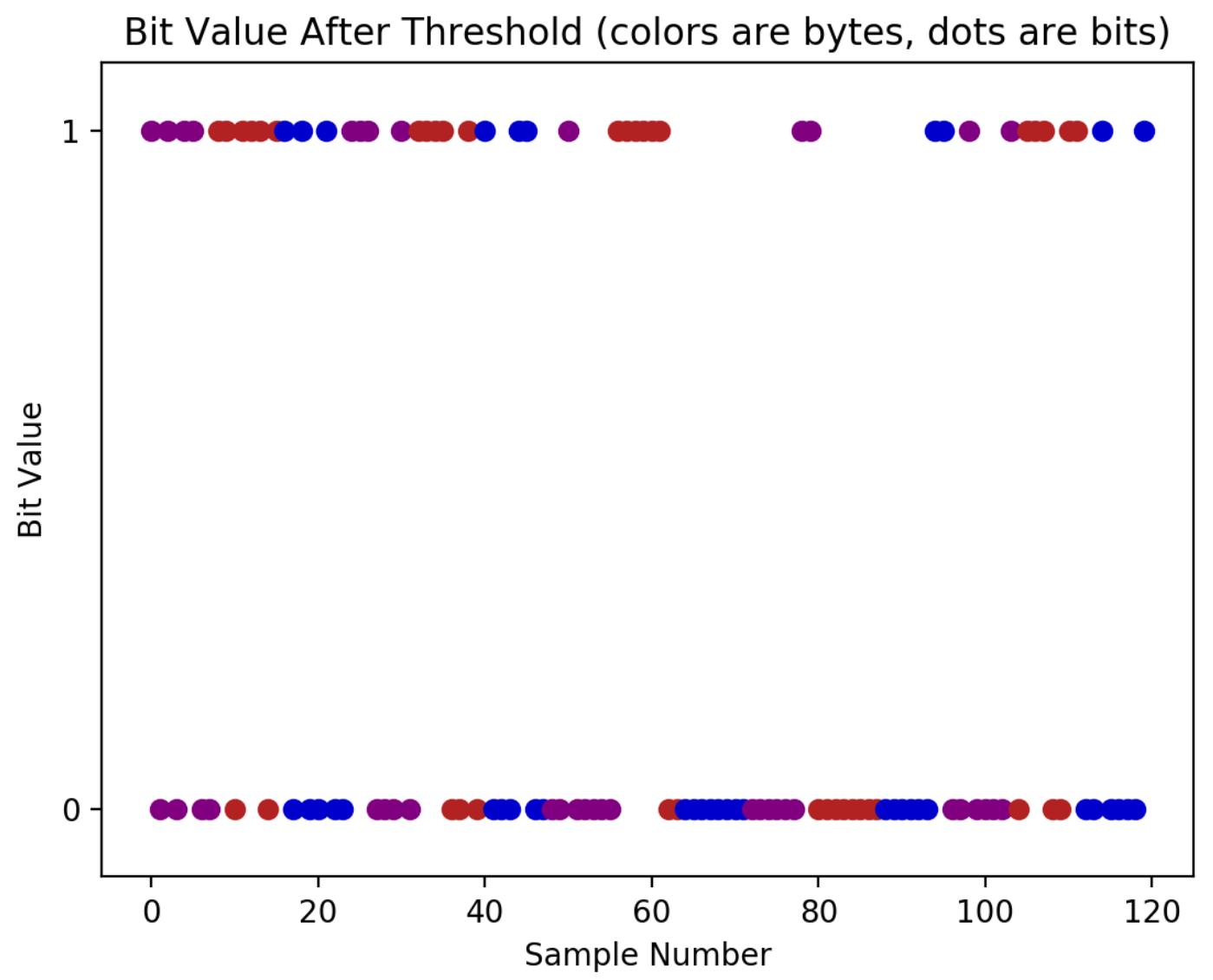

Above is received information from the threshold. We see that it follows the same pattern as the transmitted bits. 


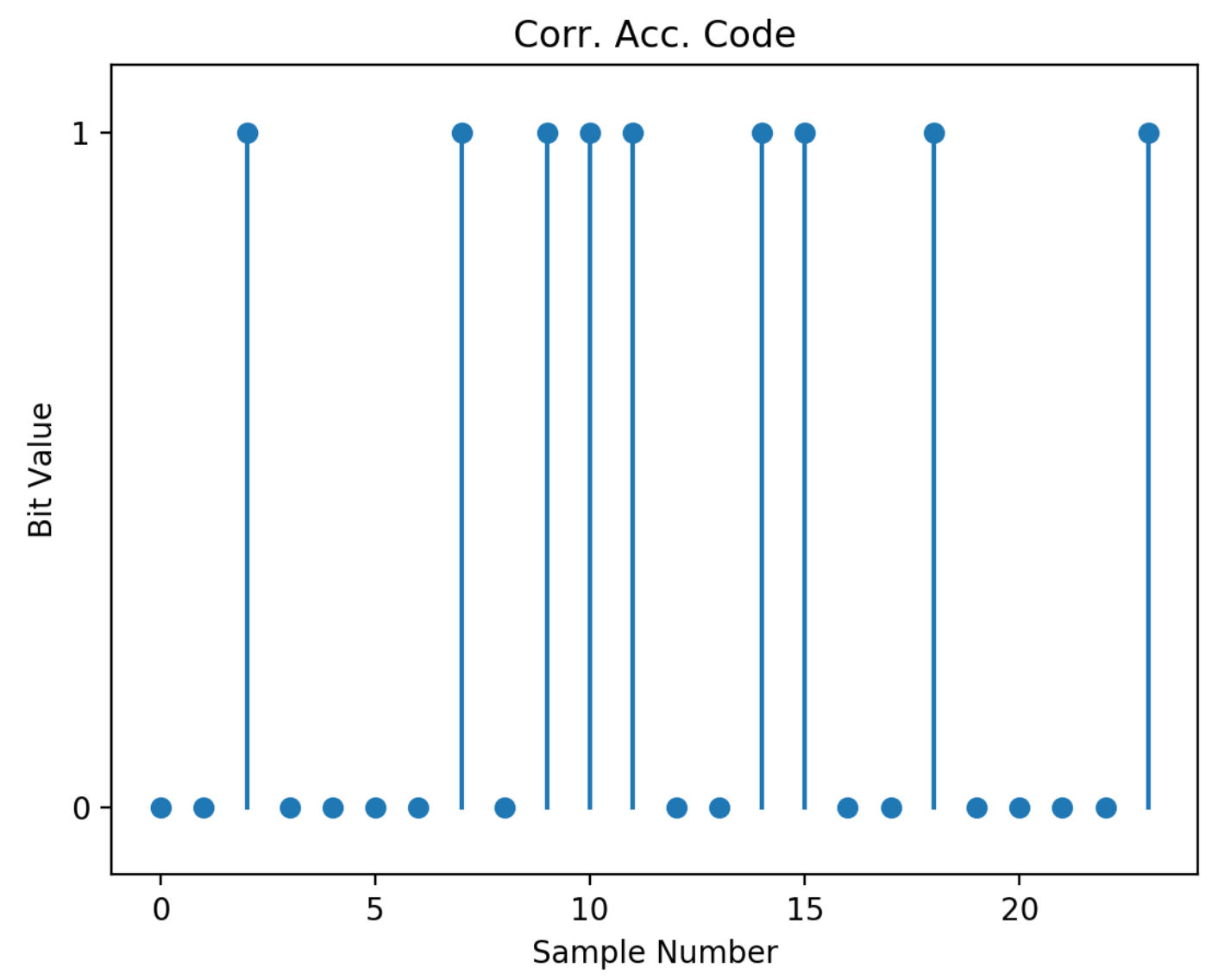




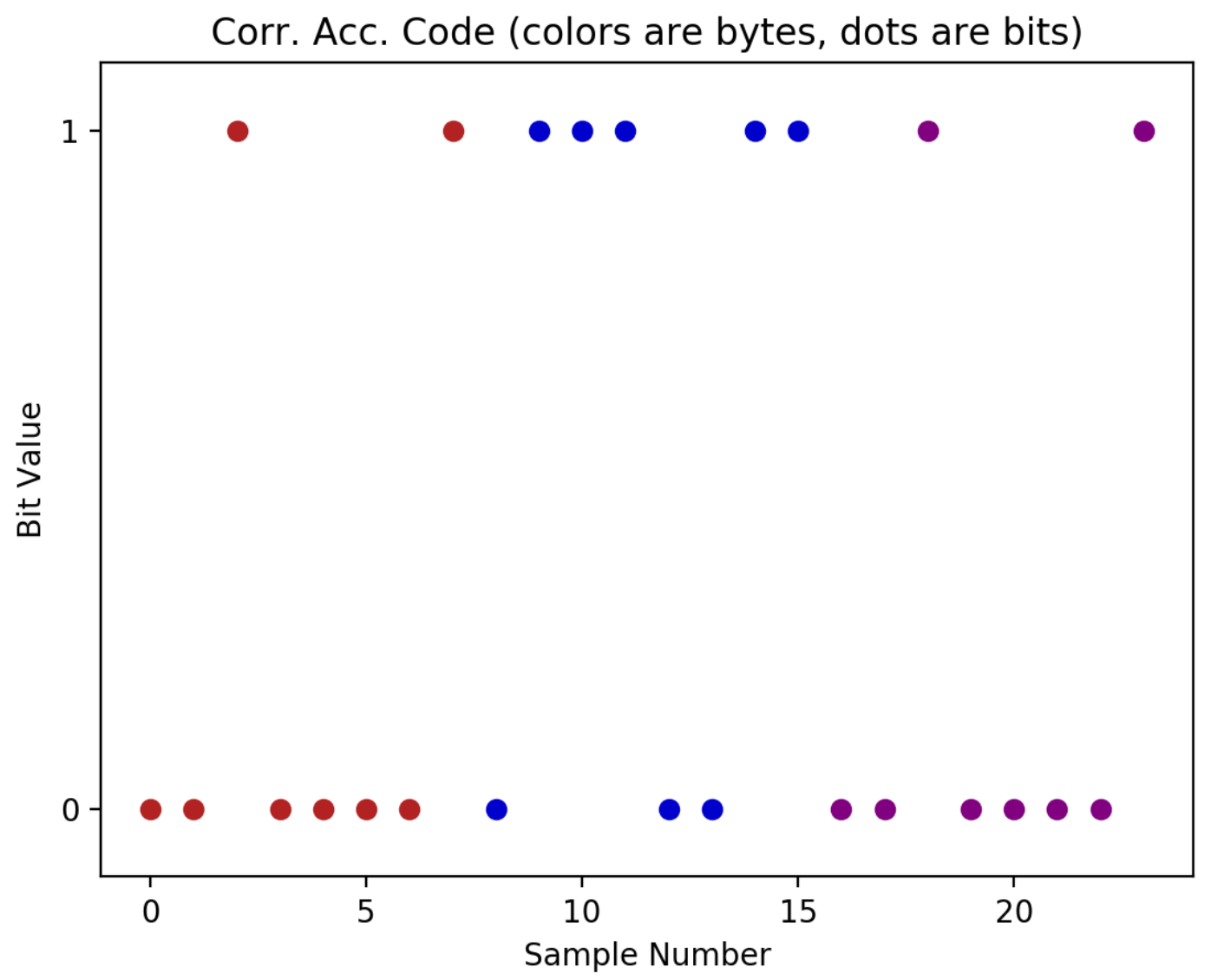

The correlate access code removes the bits from the stream that follow originate from the protocol formatter, leaving the original information. 
File Sink Input

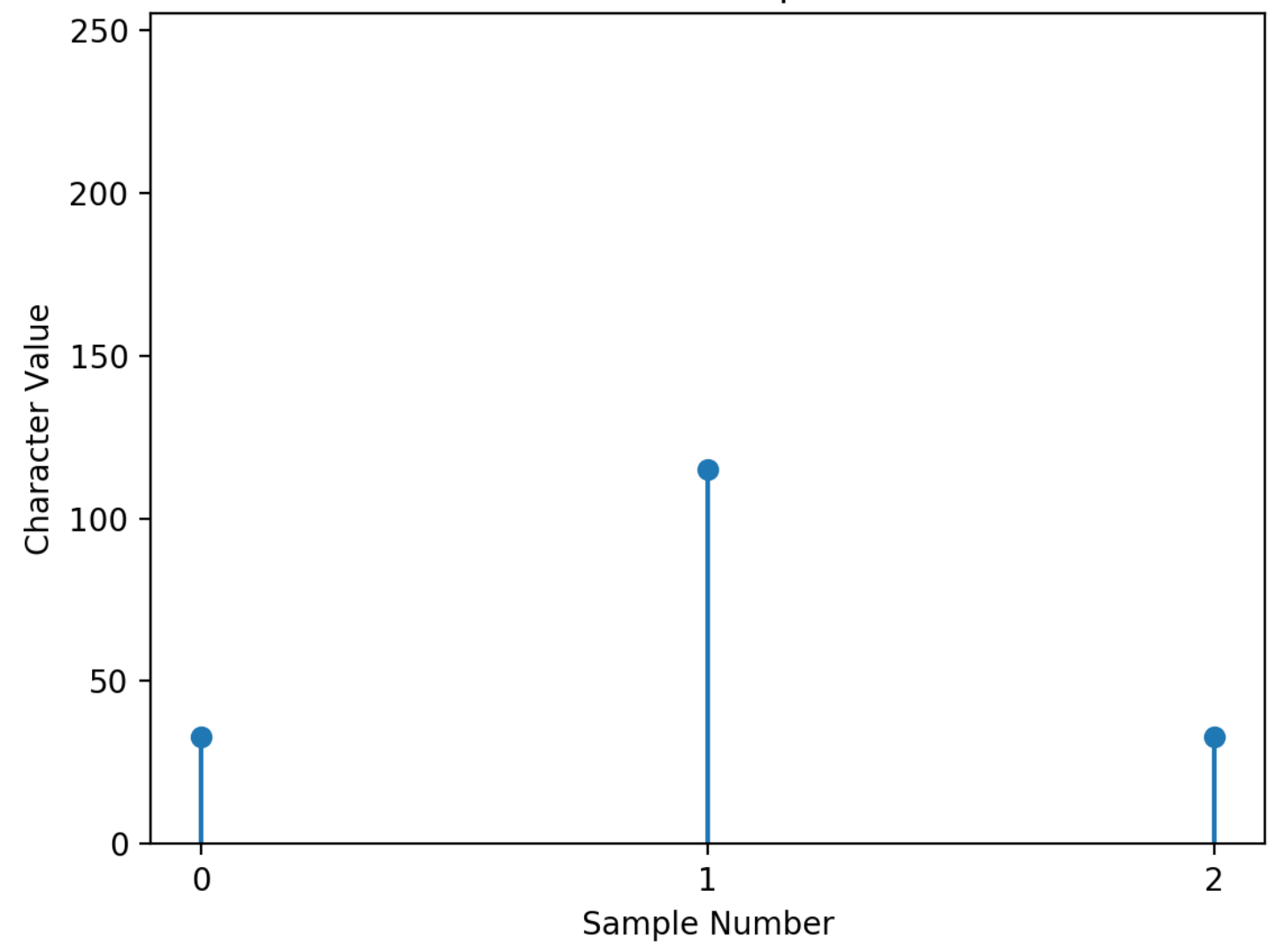


File Sink Input (colors are individual bytes)

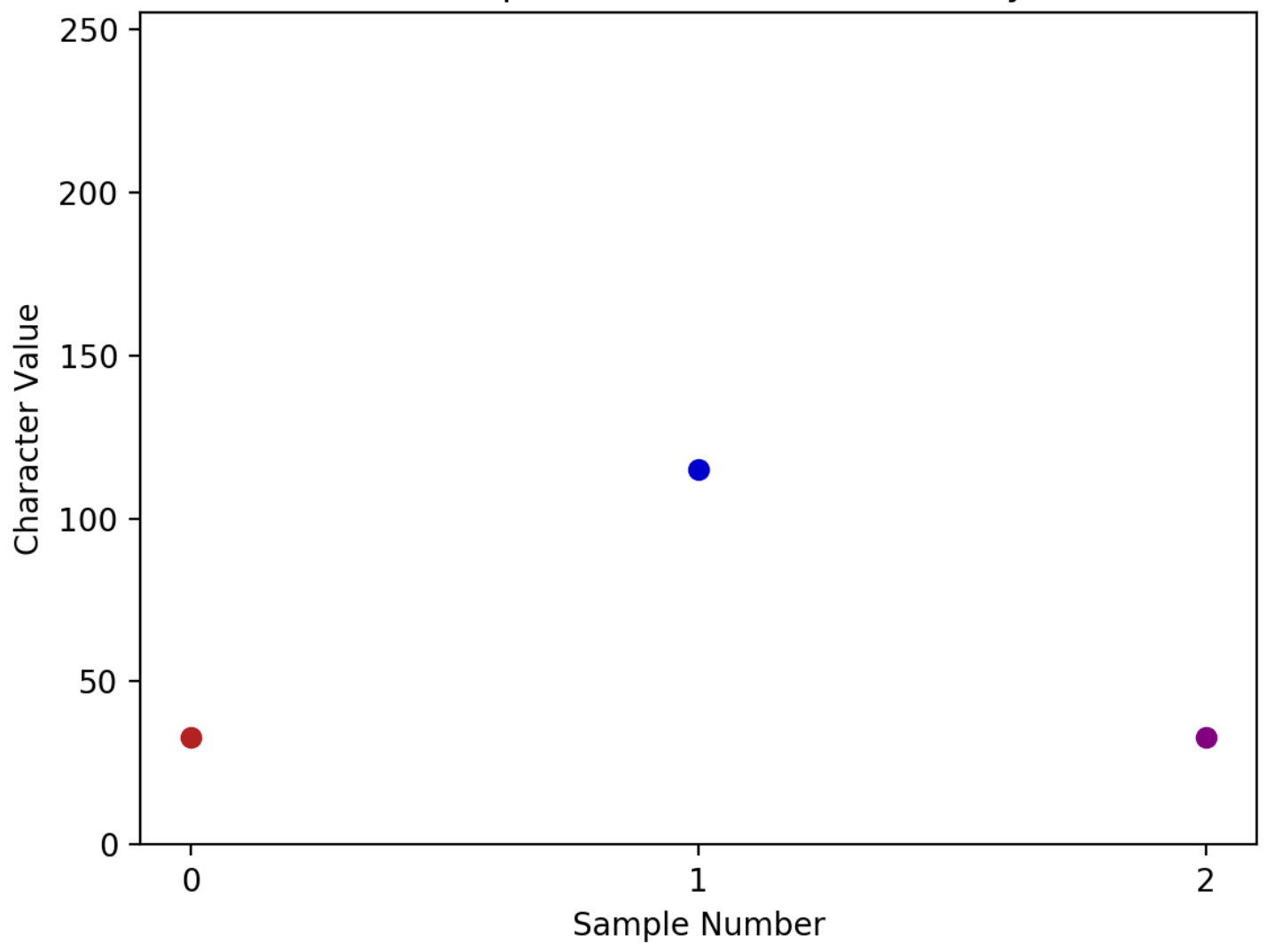

The repack bits block repacks the bits into bytes and stores the information into the file sink, successfully recovering the transmitted file.

\section{FEC simulation and testing}

In order to quantitatively test which methods are best, we set up a python script that transmitted a string of characters, similar to that of an image header file, three times with different combinations of modulation and error correction. We then compared the number output by the file source against the input of the file sink to see how effectively the data was transmitted. 

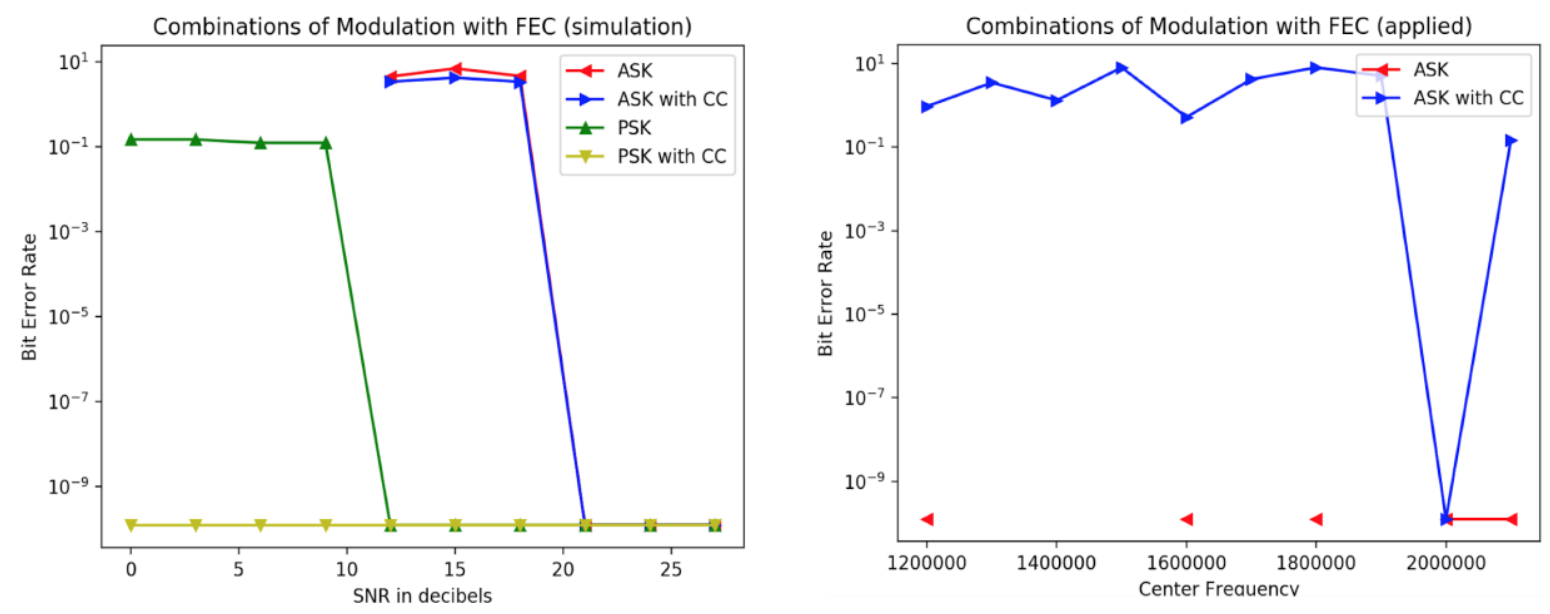

The Python code considers 4 combinations of communication channels: ASK (Amplitude Shift Keying), ASK with CC (with Convolutional front error Correction), PSK (Phase Shift Keying), PSK with CC. We ran a simulation channel that modified the SNR (Signal to Noise Ratio) by adding various voltages of AWGN (Additive White Gaussian Noise) and plotted whether or not the channel could transmit the header file of without error above.

Overall, we see that the most effective method of communication in simulation is PSK with CC, which was successful at transmitting at all SNR levels. PSK was also effective, with the bit error rate dropping sharply after 10 decibels. The $\mathrm{CC}$ technique appears to slightly increase the performance of ASK modulation.

However, due to experimental limitations, the analog to digital converter was not capable of effectively demodulating the signal transmitted through the pipe. Therefore, instead ASK and ASK with CC were tested. Interestingly, ASK either transmits perfectly or not at all at different frequencies while ASK with CC transmits at all frequencies, abet with a high error rate. Both techniques work at $2 \mathrm{Mhz}$, which suggests that the communication system prefers higher frequencies.

\section{Conclusion}

Overall, we can see the effect of each step in the GNURadio process for signal transmission. We see that passing the square wave through the communication channel leads to higher noise around the DC offset as well as a more jagged frequency response from the square wave. In order to further improve the system, we would have to lock the phase after the information is received from the Red Pitaya, as well as develop a system that helps reduce the number of samples the system needs to pass through the active gain loop before becoming decodable. 
Appendix

\begin{tabular}{|c|c|c|c|c|c|}
\hline Block & Input & Output & Parameters & Actions & Purpose \\
\hline File Source & $\begin{array}{l}\text { Text file } \\
\text { containing } \\
\text { information to } \\
\text { be sent }\end{array}$ & $\begin{array}{l}\text { Characters in } \\
\text { the file in } \\
\text { form of } \\
\text { continuous } \\
\text { stream of } \\
\text { bytes }\end{array}$ & $\begin{array}{l}\text { Output type: } \\
\text { Whether the } \\
\text { file is a } \\
\text { stream of } \\
\text { bytes, floats, } \\
\text { ints, etc; } \\
\text { Repeat: } \\
\text { Whether the } \\
\text { file will be } \\
\text { infinitely } \\
\text { repeated; }\end{array}$ & & $\begin{array}{l}\text { Opens the } \\
\text { needed data } \\
\text { file }\end{array}$ \\
\hline Throttle & - & - & $\begin{array}{l}\text { Sample Rate: } \\
\text { Number of } \\
\text { samples per } \\
\text { second }\end{array}$ & $\begin{array}{l}\text { Limits the } \\
\text { flow of } \\
\text { information to } \\
32 \mathrm{k} \\
\text { samples/sec }\end{array}$ & $\begin{array}{l}\text { Makes sure } \\
\text { computer } \\
\text { doesn't } \\
\text { overheat }\end{array}$ \\
\hline $\begin{array}{l}\text { Stream to } \\
\text { tagged } \\
\text { stream }\end{array}$ & $\begin{array}{l}\text { Continuous } \\
\text { stream of } \\
\text { characters }\end{array}$ & $\begin{array}{l}\text { Continuous } \\
\text { stream of } \\
\text { characters } \\
\text { with tagged }\end{array}$ & $\begin{array}{l}\text { Packet } \\
\text { Length: } \\
\text { Controls how } \\
\text { much data } \\
\text { stored is per } \\
\text { packet }\end{array}$ & & $\begin{array}{l}\text { Puts a } \\
\text { marker on the } \\
\text { start of a } \\
\text { packet for the } \\
\text { header } \\
\text { generator to } \\
\text { attach to }\end{array}$ \\
\hline $\begin{array}{l}\text { Protocol } \\
\text { Formatter }\end{array}$ & $\begin{array}{l}\text { Continuous } \\
\text { tagged } \\
\text { stream of } \\
\text { characters }\end{array}$ & $\begin{array}{l}\text { String of } \\
\text { header } \\
\text { characters }\end{array}$ & $\begin{array}{l}\text { Formater Obj: } \\
\text { Sets the } \\
\text { protocol } \\
\text { formatter's } \\
\text { key } \\
\text { parameters: } \\
\text { Preamble } \\
\text { and Access } \\
\text { Code, which } \\
\text { are basically } \\
\text { what the } \\
\text { correlate } \\
\text { access code } \\
\text { will look for } \\
\text { when } \\
\text { assessing } \\
\text { what is a } \\
\text { packet }\end{array}$ & $\begin{array}{l}\text { Creates a } \\
\text { header for } \\
\text { the packet }\end{array}$ & \\
\hline
\end{tabular}




\begin{tabular}{|l|l|l|l|l|l|}
\hline $\begin{array}{l}\text { Tagged } \\
\text { Stream Mux }\end{array}$ & $\begin{array}{l}\text { Two tagged } \\
\text { streams }\end{array}$ & $\begin{array}{l}\text { One tagged } \\
\text { stream }\end{array}$ & $\begin{array}{l}\text { Length tag } \\
\text { names: Input } \\
\text { the length of } \\
\text { the data } \\
\text { stream to } \\
\text { which to } \\
\text { attach the } \\
\text { header }\end{array}$ & $\begin{array}{l}\text { Combines the } \\
\text { two data } \\
\text { streams by } \\
\text { putting input } \\
1 \text { in front of } \\
\text { input } 2\end{array}$ & \\
\hline Repack Bits & 1 byte & 8 bytes & $\begin{array}{l}\text { Length tag } \\
\text { name: Input } \\
\text { the length of } \\
\text { the data } \\
\text { stream, } \\
\text { Packet } \\
\text { Alignment: } \\
\text { How packets } \\
\text { are aligned, } \\
\text { Endianness } \\
\text { MSB or LSB } \\
\text { (which one } \\
\text { comes first in } \\
\text { stream) }\end{array}$ & $\begin{array}{l}\text { Converts the } \\
\text { stream of } \\
\text { stream of bits a }\end{array}$ & $\begin{array}{l}\text { Modulation } \\
\text { techniques } \\
\text { deal with bits } \\
\text { and not bytes }\end{array}$ \\
& & & \\
& & & \\
& & & \\
\end{tabular}

Data Protocol during modulation steps

\begin{tabular}{|c|c|c|c|c|c|}
\hline Block & Input & Output & Parameters & Actions & Purpose \\
\hline Char to float & Character & Float & $\begin{array}{l}\text { Scale: Ratio } \\
\text { of Char value } \\
\text { to Float value }\end{array}$ & $\begin{array}{l}\text { Converts a } \\
\text { character } \\
\text { value of }-128 \\
\text { to } 127 \text { ( } 0 \text { and } \\
1 \text { in this case } \\
\text { as we are in } \\
\text { BITS) to its } \\
\text { numeric } \\
\text { value }\end{array}$ & $\begin{array}{l}\text { Numbers are } \\
\text { sent through } \\
\text { the channel, } \\
\text { not } \\
\text { characters }\end{array}$ \\
\hline $\begin{array}{l}\text { Rational } \\
\text { Resampler }\end{array}$ & 1 float & 600 floats & $\begin{array}{l}\text { Interpolation: } \\
\text { How many } \\
\text { samples to } \\
\text { add to the } \\
\text { stream }\end{array}$ & $\begin{array}{l}\text { Creates a } \\
\text { digital square } \\
\text { wave out of } \\
\text { single points }\end{array}$ & $\begin{array}{l}\text { We use a } \\
\text { square wave } \\
\text { to transmit } \\
\text { data }\end{array}$ \\
\hline $\begin{array}{l}\text { Moving } \\
\text { Average }\end{array}$ & $\begin{array}{l}\text { Input is a } \\
\text { stream of } \\
\text { floats }\end{array}$ & $\begin{array}{l}\text { Output is the } \\
\text { moving sum } \\
\text { of the last } \mathrm{N} \\
\text { samples, }\end{array}$ & $\begin{array}{l}\text { Length of } \\
\text { averaging } \\
\text { window, } \\
\text { number to }\end{array}$ & $\begin{array}{l}\text { Sums the last } \\
\mathrm{N} \text { points, to } \\
\text { be divided by } \\
\text { the scaling }\end{array}$ & \\
\hline
\end{tabular}




\begin{tabular}{|c|c|c|c|c|c|}
\hline & & $\begin{array}{l}\text { scaled by the } \\
\text { scale factor }\end{array}$ & $\begin{array}{l}\text { divide by, } \\
\text { max number } \\
\text { of iterations } \\
\text { in averaging }\end{array}$ & factor. This is & \\
\hline $\begin{array}{l}\text { Float to } \\
\text { Complex }\end{array}$ & Float & Complex & Scale factor & $\begin{array}{l}\text { Converts float } \\
\text { to complex } \\
\text { number } \\
\text { (magnitude) }\end{array}$ & $\begin{array}{l}\text { Succeeding } \\
\text { blocks use } \\
\text { complex } \\
\text { numbers }\end{array}$ \\
\hline $\begin{array}{l}\text { Red Pitaya } \\
\text { Sink }\end{array}$ & Complex & None & $\begin{array}{l}\text { Address: IP } \\
\text { address of } \\
\text { red pitaya to } \\
\text { connect to; } \\
\text { Port: } \\
\text { Connection } \\
\text { port; Center } \\
\text { frequency: } \\
\text { Frequency by } \\
\text { which the red } \\
\text { pitaya } \\
\text { multiplies the } \\
\text { square wave } \\
\text { by (important } \\
\text { as this is the } \\
\text { frequency at } \\
\text { which the pzt } \\
\text { oscillates); } \\
\text { Sampling } \\
\text { rate: } \\
\text { Sampling rate } \\
\text { of the red } \\
\text { pitaya } \\
\text { (basically we } \\
\text { want this as } \\
\text { high as } \\
\text { possible to } \\
\text { give the most } \\
\text { accurate } \\
\text { waveform) }\end{array}$ & $\begin{array}{l}\text { Transmits the } \\
\text { data to the } \\
\text { pzt }\end{array}$ & $\begin{array}{l}\text { Acts as a } \\
\text { digital } \\
\text { (discrete) to } \\
\text { analog } \\
\text { (continuous) } \\
\text { converter and } \\
\text { a fir filter }\end{array}$ \\
\hline $\begin{array}{l}\text { Red Pitaya } \\
\text { Source }\end{array}$ & None & Complex & $\begin{array}{l}\text { Address: IP } \\
\text { address of } \\
\text { red pitaya to } \\
\text { connect to; } \\
\text { Port: } \\
\text { Connection } \\
\text { port; Center } \\
\text { frequency: } \\
\text { Frequency by } \\
\text { which the red }\end{array}$ & $\begin{array}{l}\text { Receives the } \\
\text { data from the } \\
\text { pzt }\end{array}$ & $\begin{array}{l}\text { Acts as an } \\
\text { analog } \\
\text { (continuous) } \\
\text { to digital } \\
\text { (discrete) } \\
\text { converter and } \\
\text { a fir filter }\end{array}$ \\
\hline
\end{tabular}




\begin{tabular}{|c|c|c|c|c|c|}
\hline & & & $\begin{array}{l}\text { pitaya } \\
\text { multiplies the } \\
\text { square wave } \\
\text { by (important } \\
\text { as this is the } \\
\text { frequency at } \\
\text { which the pzt } \\
\text { oscillates); } \\
\text { Sampling } \\
\text { rate: } \\
\text { Sampling rate } \\
\text { of the red } \\
\text { pitaya } \\
\text { (basically we } \\
\text { want this as } \\
\text { high as } \\
\text { possible to } \\
\text { give the most } \\
\text { accurate } \\
\text { waveform) }\end{array}$ & & \\
\hline $\begin{array}{l}\text { Low Pass } \\
\text { Filter }\end{array}$ & Complex & Complex & $\begin{array}{l}\text { Cutoff } \\
\text { frequency: } \\
\text { Frequency to } \\
\text { attenuate }\end{array}$ & $\begin{array}{l}\text { Attenuates } \\
\text { above a } \\
\text { threshold } \\
\text { frequency }\end{array}$ & $\begin{array}{l}\text { Removes } \\
\text { high } \\
\text { frequency } \\
\text { noise as well } \\
\text { as any carrier } \\
\text { frequency to } \\
\text { leave square } \\
\text { wave }\end{array}$ \\
\hline $\begin{array}{l}\text { Active Gain } \\
\text { Control } \\
(\mathrm{AGC})\end{array}$ & Complex & Complex & $\begin{array}{l}\text { The gain is } \\
\text { updated by } \\
\text { the equation: } \\
\text { Gain = Gain } \\
\text { + Rate * } \\
\text { (Reference - } \\
\text { abs(Input)); } \\
\text { Max Gain: } \\
\text { the automatic } \\
\text { gain will not } \\
\text { exceed this } \\
\text { value. If set } \\
\text { to } 0 \text { there is } \\
\text { no max }\end{array}$ & $\begin{array}{l}\text { Applies gain } \\
\text { loop onto } \\
\text { signal }\end{array}$ & $\begin{array}{l}\text { Stabilizes the } \\
\text { signal for } \\
\text { demodulation }\end{array}$ \\
\hline AM Demod & Complex & Float & $\begin{array}{l}\text { Channel_rate } \\
\text { - incoming } \\
\text { sample rate } \\
\text { of the AM } \\
\text { baseband; } \\
\text { audio decim }\end{array}$ & $\begin{array}{l}\text { Demodulates } \\
\text { the signal }\end{array}$ & $\begin{array}{l}\text { Decimates } \\
\text { the square } \\
\text { wave }\end{array}$ \\
\hline
\end{tabular}




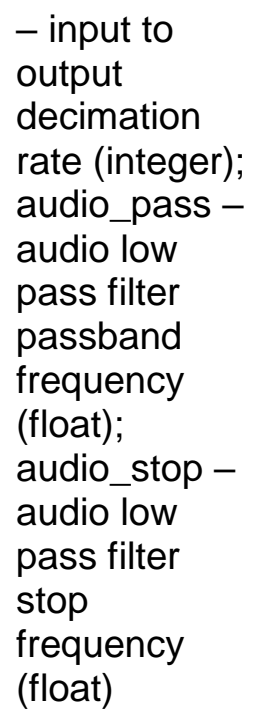

\begin{tabular}{|c|c|c|c|c|c|}
\hline $\begin{array}{l}\text { Multiply } \\
\text { Const }\end{array}$ & Float & Float & $\begin{array}{l}\text { Number to } \\
\text { multiply by }\end{array}$ & $\begin{array}{l}\text { Multiplies by } \\
\text { a constant }\end{array}$ & Fine tuning \\
\hline Add Const & Float & Float & $\begin{array}{l}\text { Number to } \\
\text { add }\end{array}$ & $\begin{array}{l}\text { Adds a } \\
\text { number }\end{array}$ & Fine tuning \\
\hline Threshold & $\begin{array}{l}\text { Float (range } \\
\text { of values) }\end{array}$ & Float (1 or 0 ) & $\begin{array}{l}\text { Upper } \\
\text { threshold, } \\
\text { lower } \\
\text { threshold }\end{array}$ & $\begin{array}{l}\text { The output } \\
\text { transitions } \\
\text { from } 0.0 \text { to } \\
1.0 \text { when the } \\
\text { input signal } \\
\text { transitions } \\
\text { from below to } \\
\text { above the } \\
\text { High level. } \\
\text { The output } \\
\text { transitions } \\
\text { from } 1.0 \text { to } \\
0.0 \text { when the } \\
\text { input signal } \\
\text { transitions } \\
\text { from above to } \\
\text { below the } \\
\text { Low level. }\end{array}$ & $\begin{array}{l}\text { The } \\
\text { thereshold } \\
\text { converts the } \\
\text { stream of } \\
\text { floats into } \\
\text { binary (bits) }\end{array}$ \\
\hline
\end{tabular}

Data Protocol after modulation steps

\begin{tabular}{|c|c|c|c|c|c|}
\hline Block & Input & Output & Parameters & Actions & Purpose \\
\hline Map & Float & Float & $\begin{array}{l}\text { Map of } \\
\text { values to }\end{array}$ & $\begin{array}{l}\text { Maps } \\
\text { incoming }\end{array}$ & $\begin{array}{l}\text { Makes sure } \\
\text { that data is }\end{array}$ \\
\hline
\end{tabular}




\begin{tabular}{|c|c|c|c|c|c|}
\hline & & & send to & data to 0 or 1 & $\begin{array}{l}\text { mapped to } \\
\text { bits }\end{array}$ \\
\hline Repack Bits & 8 bytes & 1 byte & $\begin{array}{l}\text { Length tag } \\
\text { name: Input } \\
\text { the length of } \\
\text { the data } \\
\text { stream, } \\
\text { Packet } \\
\text { Alignment: } \\
\text { How packets } \\
\text { are aligned, } \\
\text { Endianness } \\
\text { MSB or LSB } \\
\text { (which one } \\
\text { comes first in } \\
\text { stream) }\end{array}$ & $\begin{array}{l}\text { Converts the } \\
\text { information } \\
\text { from bits into } \\
\text { bytes }\end{array}$ & $\begin{array}{l}\text { Byte } \\
\text { manipulation } \\
\text { technique }\end{array}$ \\
\hline $\begin{array}{l}\text { Packed to } \\
\text { Unpacked }\end{array}$ & 1 byte & 8 bytes & $\begin{array}{l}\text { Endianness } \\
\text { MSB or LSB } \\
\text { (which one } \\
\text { comes first in } \\
\text { stream) }\end{array}$ & $\begin{array}{l}\text { Converts the } \\
\text { bytes into bits }\end{array}$ & $\begin{array}{l}\text { The correlate } \\
\text { access code } \\
\text { deals with } \\
\text { bits, not bytes }\end{array}$ \\
\hline $\begin{array}{l}\text { Correlate } \\
\text { Access Code }\end{array}$ & $\begin{array}{l}\text { Continuous } \\
\text { stream of bits }\end{array}$ & $\begin{array}{l}\text { Continuous } \\
\text { stream of bits } \\
\text { without } \\
\text { header bits }\end{array}$ & $\begin{array}{l}\text { Preamble } \\
\text { and Access } \\
\text { Code: What } \\
\text { the correlate } \\
\text { access code } \\
\text { will look for } \\
\text { when } \\
\text { assessing } \\
\text { what is a } \\
\text { packet }\end{array}$ & $\begin{array}{l}\text { Removes the } \\
\text { header bits } \\
\text { from the bit } \\
\text { stream }\end{array}$ & $\begin{array}{l}\text { The original } \\
\text { data has no } \\
\text { header bits, } \\
\text { so we want to } \\
\text { remove them }\end{array}$ \\
\hline Repack Bits & 8 bytes & 1 byte & $\begin{array}{l}\text { Length tag } \\
\text { name: Input } \\
\text { the length of } \\
\text { the data } \\
\text { stream, } \\
\text { Packet } \\
\text { Alignment: } \\
\text { How packets } \\
\text { are aligned, } \\
\text { Endianness } \\
\text { MSB or LSB } \\
\text { (which one } \\
\text { comes first in } \\
\text { stream) }\end{array}$ & $\begin{array}{l}\text { Converts the } \\
\text { bits into bytes }\end{array}$ & $\begin{array}{l}\text { Original data } \\
\text { was stored as } \\
\text { characters, } \\
\text { not bits }\end{array}$ \\
\hline
\end{tabular}

File Sink Continuous None Input type: Saves the 
stream of

characters
What kind of

information is

being written

to file;

Unbuffered:

Whether or

not the file is

being

buffered;

Append file:

Whether the

incoming

data

overwrites

the old file or append it. incoming file 


\section{Argonne}

Nuclear Science and Engineering Division

Argonne National Laboratory

9700 South Cass Avenue

Argonne, IL 60439

www.anl.gov 